\title{
Ultimate Strength of Fixed Offshore Platforms Subjected to Near-Fault Earthquake Ground Vibration
}

\author{
Hesam Sharifian, ${ }^{1}$ Khosro Bargi, ${ }^{1}$ and Mohamad Zarrin ${ }^{2}$ \\ ${ }^{1}$ School of Civil Engineering, College of Engineering, University of Tehran, Tehran, Iran \\ ${ }^{2}$ Department of Civil Engineering, K. N. Toosi University of Technology, P.O. Box 15875-4416, Tehran, Iran \\ Correspondence should be addressed to Mohamad Zarrin; mo_zarrin@sina.kntu.ac.ir
}

Received 30 January 2015; Accepted 11 May 2015

Academic Editor: Tony Murmu

Copyright (c) 2015 Hesam Sharifian et al. This is an open access article distributed under the Creative Commons Attribution License, which permits unrestricted use, distribution, and reproduction in any medium, provided the original work is properly cited.

\begin{abstract}
The pile foundation nonlinearity and its influence on the ultimate capacity of fixed platforms have not comprehensively been covered by previous researchers. In this study, the seismic behavior and capacity of a newly designed and installed Jacket Type Offshore Platform (JTOP) located in the Persian Gulf is investigated by conducting Incremental Dynamic Analysis (IDA) using a suit of nearfault ground motions. Additionally, two modified models of the original platform are created by slightly increasing the diameter of the pile foundation and also softening the jacket part for evaluating the importance of the pile foundation and seismic soil-pile structure interaction on the dynamic characteristics of the JTOPs. Valuable discussions are provided to explore various aspects of the dynamic behavior of JTOPs by presenting individual and multirecords IDA curves using effective Engineering Demand Parameters (EDPs). Comparing the results of the three platform collapse fragility curves, it is concluded that the pile foundation plays a very important role in the dynamic response of offshore platforms and can drastically alter the ultimate strength of the platform together with its collapse capacity. It is observed that the proportional distribution of nonlinear behavior in the pile foundation and jacket part is the key factor in the enhancement of the ultimate strength of JTOPs. On the basis of the results derived from this paper, it is recommended that some basic requirements should be developed in order to ensure that the coupling ductility of pile foundation and jacket part is optimized during the design process. Furthermore, according to the findings from this study, some practice recommendations are presented to be devised within the design step.
\end{abstract}

\section{Introduction}

Among all lateral loadings acting on the pile supported structures, in seismically active areas, these structures may be subjected to strong ground motions where the behavior of pile foundations under lateral seismic loads becomes an important factor in efficiently assessing the performance of such structures. Jacket Type Offshore Platform (JTOP) is one of the most important pile supported structures in exploration and production of oil and natural gas. Pile foundations are an essential structural component of JTOPs, and the seismic soil-pile-superstructure interaction (SSPSI) is an important issue in the seismic behavior of this kind of structure. Strong ground motions have been a major cause of past damage in pile foundations and reliably evaluating the dynamic response of pile foundations against this type of lateral loading plays a paramount role in JTOPs design procedure.

The ultimate strength and nonlinear dynamic behavior of JTOPs subjected to earthquake ground motions have been the subject of a number of research papers in recent years. However, many of the previous works have used static pushover procedure to evaluate ultimate capacity, seismic reliability, and seismic assessment of offshore platforms under earthquake load patterns (Gates et al. [1], Kayvani and Barzegar [2], Mortazavi and Bea [3], Asgarian and Agheshlui [4], and Golafshani et al. [5]). The ultimate strength, hysteretic response of tubular members, and cyclic inelastic behavior of jacket frames of JTOPs ignoring pile foundation part were investigated in the works of Zayas et al. [6], Kayvani and Barzegar [2], Mortazavi and Bea [3], Honarvar et al. [7], and Golafshani et al. [8] using experimental results of frames 
tested under monotonic increasing static loads or pseudo static cyclic displacement histories. In the works of Bea and Young [9], Peng et al. [10], Bargi et al. [11], and El-Din and Kim [12] the nonlinear dynamic response and performance characteristics of JTOPs were studied by subjecting the platform to individual earthquake time histories at a special level of intensity, for example, ductility level earthquake. Ou et al. [13] carried out a comprehensive experimental and numerical study in order to examine the vibration control effectiveness of the damping isolation system composed of rubber bearings and viscous dampers for a prototype fixed base jacket platform. Similarly, Mousavi et al. [14] evaluated the optimum parameters of tuned liquid column-gas damper, TLCGD, and its efficiency when the platform was subjected to seismic excitation. The jacket structure was considered a shear-flexural cantilever beam fixed at the base in their work. Li et al. [15] developed a convenient method of applying wavelet transform to multicomponent earthquake motions to determine the critical incidence of the seismic wave from the viewpoint of the input energy of structures. The soil-pile system was excluded from their numerical jacket model. A new robust and practical Beam on Nonlinear Winkler Foundation model was presented by Memarpour et al. [16] for cyclic lateral behavior of pile foundation of Fixed Platforms, which could be utilized for seismic analysis. However, the behavior of the piles in their case study fixed platform was investigated under wave lateral cyclic and monotonic loadings. Recently, a practical and accurate approach named Incremental Dynamic Analysis (IDA) was proposed by Vamvatsikos and Cornell [17] for the prediction of seismic demands from elastic behavior to yielding and, finally, collapse capacity of structures. A fundamental step in IDA is to perform a series of nonlinear dynamic analyses of structures under a suit of multiple earthquake ground motion records, each scaled to several intensity levels so that it covers the whole range of response. To capture the nonlinearity in piles, Assareh and Asgarian [18] conducted several multirecords IDA analysis on single piles of JTOPS. Asgarian and Ajamy [19] investigated the seismic performance of three newly designed JTOPs using IDA analysis procedure. El-Din and Kim [20] utilized IDA procedure for obtaining the ultimate capacity of the fixed-based jacket offshore platforms with various bracing configurations. The main shortcoming of the two later works was that the soilpile-structure interactions were ignored and the pile foundation was replaced by equivalent pile stubs. In light of previous studies, the pile foundation's nonlinearity and its systematic influences on the seismic ultimate capacity of JTOPs have not comprehensively been covered by previous researchers. This concluding remark was also emphasized in a state-ofthe-art review paper on seismic response and behavior of Fixed Offshore Platforms (Hasan et al. [21]). The review suggests that most of the previous analyses are based on hydrodynamic loadings only and that very few investigators have accounted for the seismic criteria of offshore structures. They concluded that more realistic models including soilstructure interaction with multidegrees of freedom need to be analyzed.
Recently, El-Din and Kim [12] investigated the effects of both aleatory and epistemic uncertainty on the seismic response parameters of an existing offshore platform. This study revealed that the uncertainty in soil-pile axial friction has a notable impact on the response parameters. The effect of soil lateral capacity uncertainty on seismic response was neglected in this research. While their study is insightful to the effects of various parameter uncertainties on the general response of platform, they did not study the effects of using different design strategies or parameters on the nature of platform seismic response rather than the general maximum response. Furthermore, the site response analysis of soil was not conducted and it was assumed that the time history of earthquake loading was directly applied to the platform model. This will exclude the influences of soil farfield nonlinearity, as well as the kinematic interaction effects, on the dynamic response of the platform.

This paper investigates the seismic behavior of a newly designed and installed Jacket Type Offshore Platform located in the Persian Gulf by conducting Incremental Dynamic Analysis (IDA). A suit of 10 pulse-type near-fault ground motion records is selected to perform dynamic analysis. Near-source ground motions, especially those containing forward directivity effects, impose high seismic demands on the structure and, therefore, are considered suitable for the purposes of evaluating ultimate strength and collapse mechanism of a strong structure such as JTOPs. Moreover, to date, the effects of near-source ground motions on JTOPs have not been investigated in previous works. Additionally, two modified models of the original platform are created by slightly increasing the diameter of the pile foundation and also softening the jacket part for evaluating the importance of pile foundation and seismic soil-pile structure interaction in the dynamic characteristics of the JTOPs. Some individual and multirecords IDA curves in terms of maximum storeylike drift ratio per unit length of pile and maximum interstorey drift ratio of jacket bracing storeys are provided and valuable discussions are presented to explore various aspects of the dynamic behavior of JTOPs. Based on the findings from this study, some practice recommendations are presented to be devised within the design step. Finally, by presenting collapse fragility curves for all three models, the effects of the pile foundation and, similarly, the proportionality of the stiffness and strength of the pile foundation and jacket part of the platform on the ultimate collapse probability of considered platforms are investigated.

\section{Ground Motion Records Used in This Study}

Prior to performing nonlinear dynamic analysis, a number of ground motion records must be selected. 10 records out of a set of 40 unscaled three-component ground motions (Baker et al. [22]) containing strong velocity pulses of varying periods in their strike-normal components have been selected. Pulse-type near-field ground motions resulting from directivity effects are characterized by a distinct, high intensity pulse in the velocity time history of motion, in a direction perpendicular to the fault rupture plane. These ground motions are expected to occur at sites near the fault 
where the fault rupture propagates towards the site, and the slip direction (on the fault plane) is aligned with the rupture direction (Somerville et al. [23]). The reason for choosing pulse-type ground motions in this study is that, in these motions, most of the energy from the rupture is concentrated in a single long period pulse of motion at the beginning of the seismogram, and this phenomenon transmits into the structure a large amount of energy, which should be dissipated in a short time through relatively few plastic cycles, causing the structure to undergo large inelastic displacements. Given this feature, these high seismic demands from forward directivity records are suitable for the purposes of evaluating ultimate strength and collapse mechanism of a strong structure such as Jacket Type Offshore Platform which is studied in this work. According to historic earthquake data near the location of the considered case study platform, an estimated 6.8-magnitude earthquake long decades ago (Ambraseys and Melville [24]) as well as a 6-magnitude earthquake in 2005 [25] have occurred just a few kilometers away from the current location of the platform. This historic information emphasizes the need for a detailed study on the dynamic behavior of the case study platform subjected to near-fault ground motions. Furthermore, reviewing the Iranian tectonic setting, the region of interest is located near the NNW trending ZendanMinab-Palami fault zone which marks the western limit of the Makran subduction zone and connects the western Makran to the eastern Zagros deformation domain (Hessami and Jamali [26]). The most recently determined focal depths (8$14 \mathrm{~km}$ ) imply that moderate-to-large earthquakes can occur in the uppermost part of the Arabian basement, beneath the Hormuz Salt Formation (the location of platform) [26, 27]. It is apparent that the results of the investigations herein are attributed to near-field particular motion type. Extending the results to other types of records would require either paying particular attention to the differences between the characteristics of these motions and non-pulse-type near-fault and far-field earthquakes, as well as their effects on the structural response, or verifying the observations documented in this study for other types of earthquakes in a separate study. It would be valuable to conduct similar dynamic analysis on a suit of far-field records. Since the JTOPs are huge structures with many elements and components, the computational expenses are high. Consequently, regarding the aforesaid goal of this study, the analyses are only provided for near-field records. However, some preliminary analyses by subjecting the original platform to some representative far-field earthquake motions revealed consistent failure modes of response with near-field analyses results [28].

The original suit of 40 records is a standardized set of ground motions selected as a part of the PEER Transportation Systems Research Program (TSRP) [29] with the goal of studying a wide variety of structural and geotechnical systems at a wide range of locations in active seismic regions. The mean and variance logarithmic response spectrum of the record set are depicted in Figure 1. Since the ground motion set is not structure-specific or site-specific, the selected records have a variety of spectral shapes over a wide range of periods. As it is seen from Figure 1, this record suit has a large and approximately constant variance around the mean

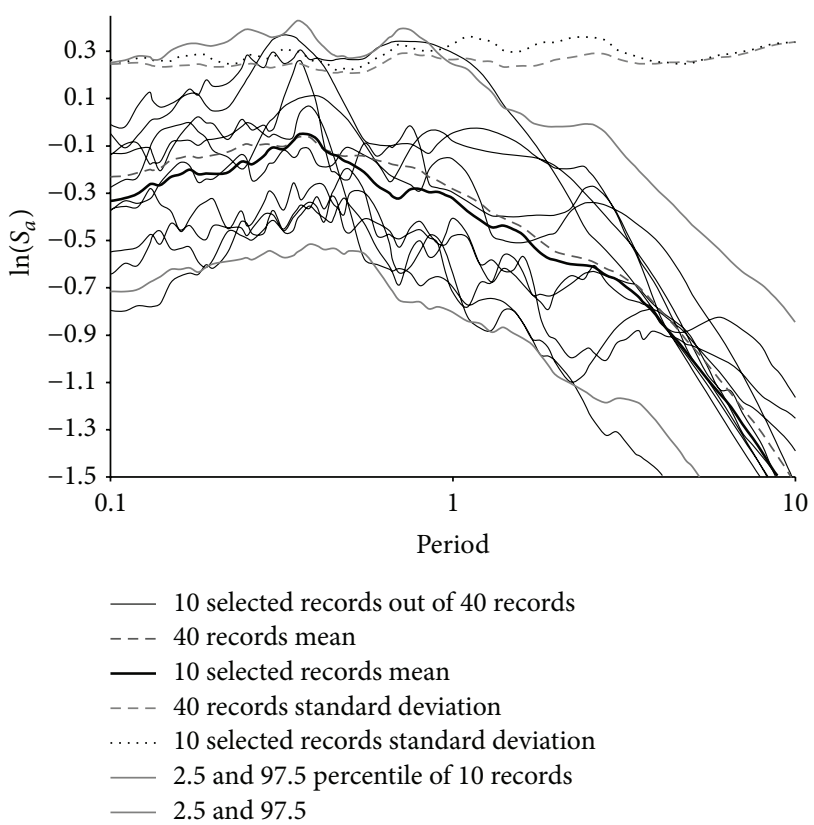

FIGURE 1: The logarithmic response spectrum of individual records and their logarithmic mean and variance.

spectral values of different periods. The later feature guarantees that earthquake records with a range of properties are available for analysis and ground motion aleatory variability can be captured in the case that the analyst is interested in evaluating the impact of ground motion variance on the structural response estimates. From another point of view, when investigating the behavior of the structure near its final capacity as is the case in this study, occurrence of nonlinearity makes the structure sensitive to excitation at a wide range of periods; thus, utilizing a set of records with variance in a broad band would be beneficial in highlighting various modes of behavior. Additionally, these 40 ground motions were chosen to have a variety of pulse periods. An important feature of pulse-type earthquakes is that the structural response is a function of the ratio of the pulse period to the modal periods of the structure. Therefore, any selected suit of records should cover a variety of pulse periods.

In the course of this study, careful attention has been paid to the selection of 10 records in a manner that they inherit the important aforementioned features of the original suit of 40 records such as statistical properties and variation in pulse period, magnitude, PGV, and duration. From Figure 1, it is apparent that the logarithmic mean and standard deviation of these 10 records match fairly well with the original record set, especially in periods larger than the fundamental period of the structure. This ensures that the statistical properties of the two record sets remain equivalent. Tabulated in Table 1 are the designation and basic properties of the selected records. Additionally, depicted in Figure 2 are the histograms of pulse periods, strike-normal peak ground velocities, and duration of selected records. According to Figure 2(a), the pulse periods of selected records cover a wide band. Three records have their ratio of pulse period to fundamental period of JTOP 


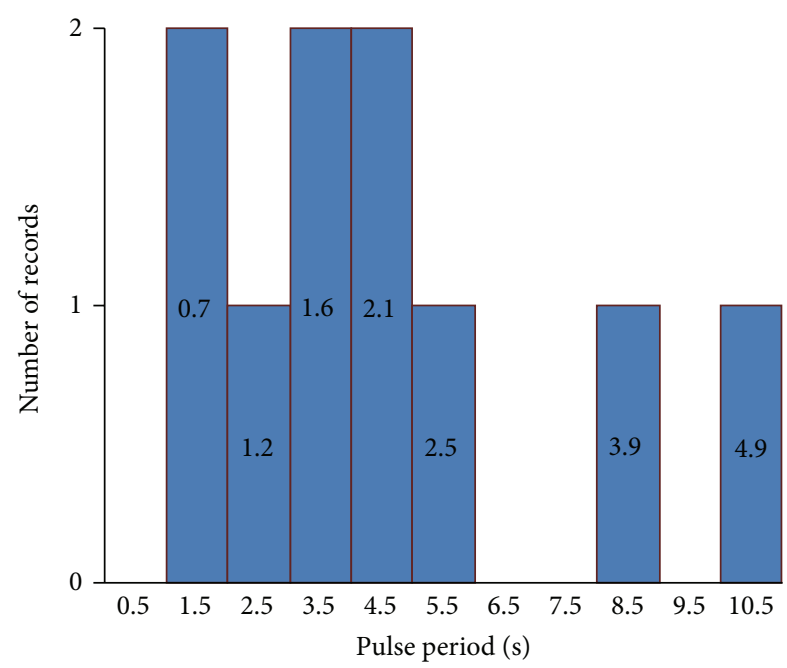

(a)

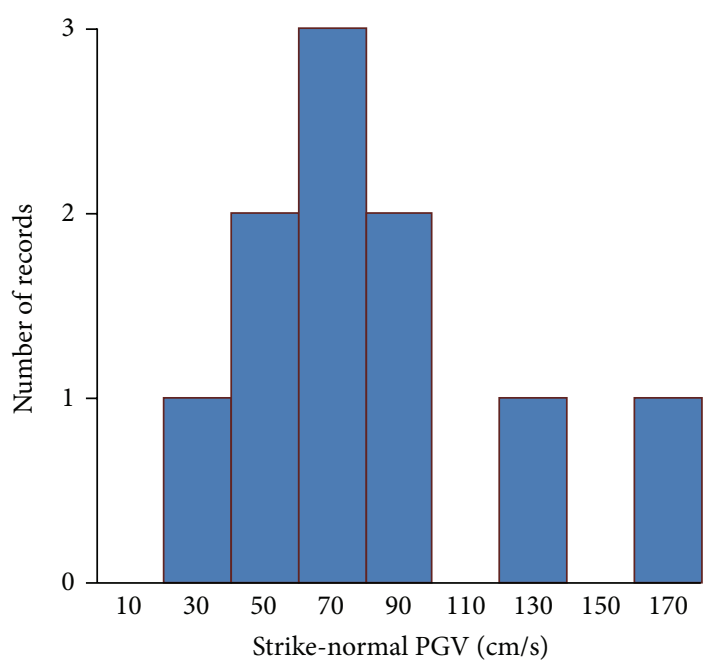

(b)

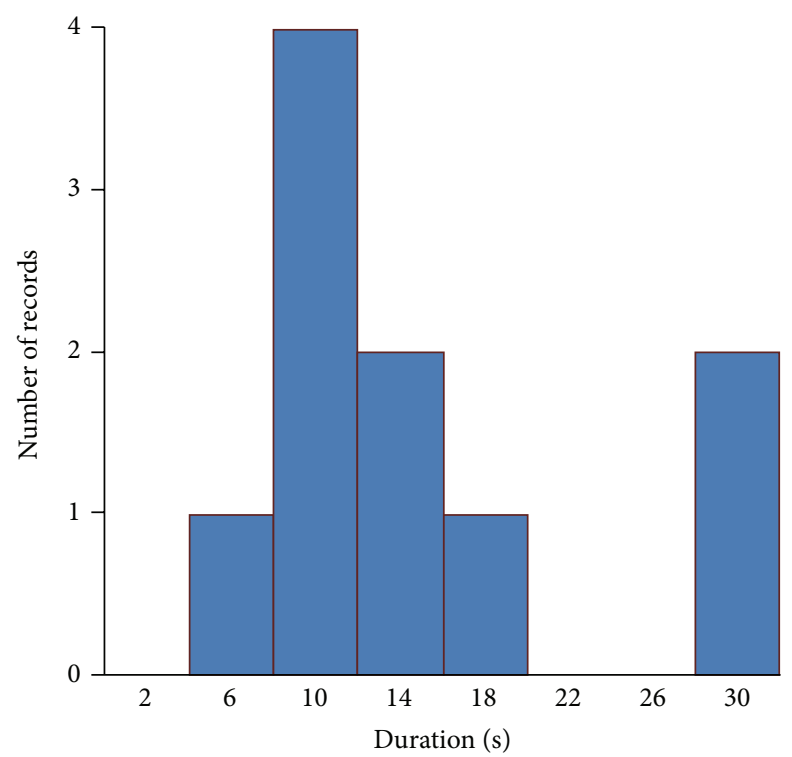

(c)

FIGURE 2: Histogram of (a) pulse periods. (The ratio of pulse period to fundamental period of JTOP is labeled on the histogram.) (b) Strikenormal peak ground velocities. (c) Significant duration (2.5\% to $97.5 \%$ AI) of selected records.

smaller or equal to one; two records have this ratio equal to 1.5; for two other records, this ratio is around 2 while, for the three remaining records, the aforesaid ratio is larger than 3 . These motions cover a magnitude range of 6.53 to 7.62 and a closest distance ranging from 3.95 to $10.92 \mathrm{~km}$. Strike-normal peak ground velocities range from 30 to $167 \mathrm{~cm} / \mathrm{sec}$ with a mean of $80 \mathrm{~cm} / \mathrm{sec}$, indicating that these ground motions are generally very intense (see Figure 2(b)). The selected ground motions come from earthquakes with a variety of rupture mechanisms. Another important parameter that has been known to be influential on structural response is record duration. Duration of record is an indirect representation of earthquake magnitude. Careful consideration is given to the selection of records with various durations. The durations of record set have been chosen to range from a small value of
7.07 seconds to a large value of 29.07 seconds with a mean value equal to $14.75 \mathrm{sec}$.

\section{Case Study Platform Description}

The selected case study platform for seismic investigation is named HE2 platform, which was planned and designed in 2010 and was installed in 2012. The installed location of this platform is the Persian Gulf near the Hengam island and strait of Hormoz. The water depth in the central location of the platform is $74.6 \mathrm{~m}$. This platform was designed and analyzed on the basis of the recommendations of API RP2A-WSD [30].

The jacket part of the platform consists of four braced storeys and the perimeter legs of the jacket are battered to $1: 10$ in one row and are straight in the other rows. The utilized 

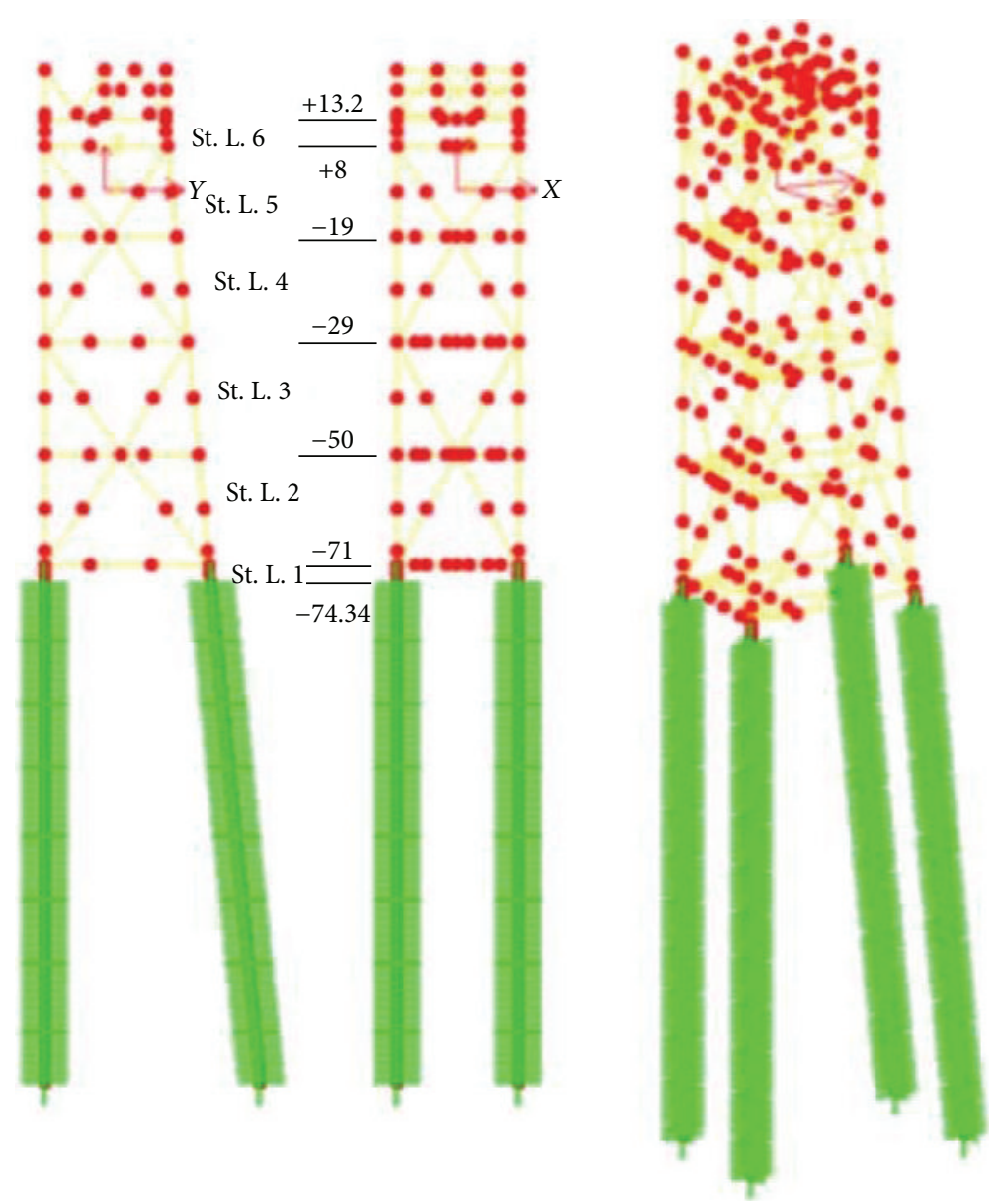

FIgURE 3: The schematic configuration of the developed numerical model.

TABLE 1: The designation and basic properties of the selected records.

\begin{tabular}{cccccc}
\hline$\#$ & $\begin{array}{c}\text { NGA record } \\
\text { sequence } \\
\text { number }\end{array}$ & $\begin{array}{c}\text { Earthquake } \\
\text { name }\end{array}$ & $\mathrm{Mw}$ & $\begin{array}{c}R^{\mathrm{a}} \\
(\mathrm{Km})\end{array}$ & $\begin{array}{c}\mathrm{Vs} 30 \\
(\mathrm{~m} / \mathrm{s})\end{array}$ \\
\hline 1 & 170 & $\begin{array}{c}\text { Imperial } \\
\text { Valley-06 }\end{array}$ & 6.53 & 7.31 & 192 \\
4 & 180 & $\begin{array}{c}\text { Imperial } \\
\text { Valley-06 }\end{array}$ & 6.53 & 3.95 & 206 \\
10 & 763 & Loma Prieta & 6.93 & 9.96 & 730 \\
14 & 982 & Northridge-01 & 6.69 & 5.43 & 373 \\
17 & 1045 & Northridge-01 & 6.69 & 5.48 & 286 \\
18 & 1063 & Northridge-01 & 6.69 & 6.50 & 282 \\
21 & 1086 & Northridge-01 & 6.69 & 5.30 & 441 \\
24 & 1161 & Kocaeli, Turkey & 7.51 & 10.92 & 792 \\
30 & 1494 & Chi-Chi, Taiwan & 7.62 & 5.30 & 461 \\
38 & 1530 & Chi-Chi, Taiwan & 7.62 & 6.10 & 494 \\
\hline
\end{tabular}

${ }^{\mathrm{a}}$ Closest distance.

lateral resisting system of the jacket are the chevron-type and inverted chevron-type bracing systems, which constitute an X-shape (Split X Bracing System) at the connection points of the second and fourth storey levels (see Figure 3). The reason why the legs are straight in one row is because of the berthing of Jack-up drilling platform besides the fixed platform. The plan of the jacket at working point is square shaped with base dimension of $23 \mathrm{~m}$, which extends with the aforementioned batter and becomes $31.53 * 23 \mathrm{~m}$ at mud line elevation.

The platform is supported by 4 main piles, which are driven to $80 \mathrm{~m}$ penetration. The diameter of the piles is $1.32 \mathrm{~m}$ and its wall thickness is equal to $5.5 \mathrm{~cm}$. The whole mass of the deck is 2810 ton including structural components, mechanical instruments, bridge reaction on deck, operating forces applied by the lifts, pipe masses, and 20 percent of live loads. This general mass was considered to be lumped masses in all nodes of the deck. Furthermore, these masses are converted to loads and have been applied to deck nodes in a separate gravity loading analysis. The mass of the jacket including structural component masses, marine growth mass, added mass, and internal water mass is equal to 4985 ton, which is considered to be lumped mass in jacket nodes at corresponding elevations of the jacket.

In order to perform dynamic analysis and define fundamental mode shapes of the structure, it is required that the dynamic mass matrix of the structure be established. In line with this, for defining dynamic masses in longitudinal, transversal, and vertical direction, the structural elements 
TABLE 2: Design soil parameters for dynamic analysis.

\begin{tabular}{|c|c|c|c|c|c|c|c|}
\hline \multirow{2}{*}{ Layer } & \multirow{2}{*}{ Soil } & \multicolumn{2}{|c|}{ Depth $[\mathrm{m}]$} & \multirow{2}{*}{$\gamma^{\prime}\left[\mathrm{KN} / \mathrm{m}^{3}\right]$} & \multicolumn{2}{|c|}{ Shear strength $[\mathrm{KPa}]$} & \multirow{2}{*}{$\varepsilon(50)[-]$} \\
\hline & & From & To & & From & To & \\
\hline 1 & Sand & 0 & 2.1 & 6.5 & & & \\
\hline 2 & Clay & 2.1 & 3.7 & 8 & 55 & 55 & 0.005 \\
\hline 3 & Clay & 3.7 & 8 & 9 & 65 & 115 & 0.004 \\
\hline 4 & Clay & 8 & 26.4 & 9 & 115 & 176 & 0.004 \\
\hline 5 & Clay & 26.4 & 35 & 9 & 164 & 175 & 0.004 \\
\hline 6 & Clay & 35 & 48.3 & 9.5 & 188 & 230 & 0.004 \\
\hline 7 & Sand & 48.3 & 49.2 & 10 & & & \\
\hline 8 & Clay & 49.2 & 61 & 9.5 & 234 & 288 & 0.004 \\
\hline 9 & Clay & 61 & 63.1 & 9.5 & 288 & 288 & 0.004 \\
\hline 10 & Clay & 63.1 & 85 & 9.5 & 288 & 320 & 0.004 \\
\hline 11 & Clay & 85 & 93.6 & 9.5 & 330 & 460 & 0.004 \\
\hline 12 & Clay & 93.6 & 100 & 9.8 & 460 & 460 & 0.004 \\
\hline 13 & Clay & 100 & 110.5 & 9.3 & 460 & 530 & 0.004 \\
\hline
\end{tabular}

and other component masses considering all aforementioned masses are specified at the nodes of both ends of the elements.

Based on the in situ drilled soil borings and the geotechnical investigations performed on the sampled soil, the layering profile of the soil at the platform location is characterized as detailed in Table 2. On the basis of this soil layering information, the parameters required for defining $p-y, t-z$, and $\mathrm{q}-\mathrm{z}$ elements, which will be described in next section, can be determined for a unit length of soil profile. A numerical model of this platform is developed using the Open System for Earthquake Engineering Simulation (OpenSees) computer program (Mazzoni et al. [31]). The schematic configuration of the developed numerical model in OpenSees is illustrated in Figure 3. As it can be seen in this figure, the frames of the jacket have both battered and straight legs which is associated with the phenomenon that the jacket is not symmetric and has different stiffness along its two major directions. Consequently, in order to avoid torsional response when the earthquake loadings are applied, dynamic analyses have been performed along the direction $y$, where the jacket is symmetric.

In order to verify the developed analytical model and make sure that the model is working appropriately, the calculated modal periods of the structure by OpenSees are compared to the computed periods of Sacs 5.2 software. The fundamental period of the structure obtained using OpenSees is 2.16 seconds, which is fairly in agreement with its corresponding value of 2.12 seconds calculated by Sacs 5.2 software. Increasing the pile diameter to $1.42 \mathrm{~m}$ with a wall thickness of $5.8 \mathrm{~cm}$, a modified model of the platform is created in OpenSees program, which will be denoted in the following sections as PSP platform (Pile Strengthened Platform). In addition to this, another model of platform denoted hereafter as JS platform (jacket-softened platform) is created by softening the legs of the jacket as a result of the reduction of its diameter from $1.4542 \mathrm{~m}$ to $1.402 \mathrm{~m}$, as well as reducing the diameter of the pile inside legs from $1.3208 \mathrm{~m}$ to $1.2708 \mathrm{~m}$. Furthermore, the bracing elements of the jacket are modified in such a way that the critical compressive buckling load of brace members in storey levels $1,2,3$, and 4 are reduced by $34 \%, 40 \%, 40 \%$, and $35 \%$ respectively. The fundamental period of the structure in this new model is $2.28 \mathrm{sec}$. It should be emphasized that the pile elements in this model remained constant.

\section{Characteristics of the Developed Numerical Model}

For the purpose of simulating the response of pile and jacket member elements, nonlinear beam-column elements with distributed plasticity whose analytical formulation is on the basis of flexibility method with or without iteration are used. The fiber discretization approach has been utilized for modeling the cross section of pile and jacket elements. The general geometric configuration of a fiber cross section is divided into several tiny components with various simple shapes such as square, rectangle, and triangle. The feasibility of creating a cross section of member with these subregion components provides appropriate flexibility in definition of sections composed of different materials. The geometric features considered for each of the fibres are the local $x$ and $y$ coordinates of fibers and their area. The continuity equation of the section is computed on the basis of the stress-strain relationships of the material used. The assumed material for the fibers is considered uniaxially and the strain in each fiber is calculated based on the strain at centroid strain and curvatures at the sections, considering Bernoulli's assumption that plane sections remain plane and normal to element axis after bending. An example of a section comprising different types of materials is the leg element of the jacket with the pile element located inside it. In some cases, the space between the leg and pile is filled with grout. Therefore, defining the section with fiber approach is the most suitable choice for leg members of offshore platforms. The assigned stress-strain relationship for the steel material 
of the pile and jacket members for this research is the Menegotto-Pinto model (Menegotto and Pinto [32]). One of the advantages of this type of material is the gradual transition from linear region to nonlinear range of response. Furthermore, the cyclic behavior of this material is fairly consistent with experimental tests including Bauschinger effects.

Using force-based nonlinear beam-column elements along with fiber approach, the section stiffness matrix in the section level is converted to element stiffness matrix at basis system degrees of freedom at both ends of the element. Then, the element stiffness matrix may be transformed from basic element to the element local degrees of freedom and, finally, to the global degrees of freedom by a matrix transformation (de Souza [33]). The so-called matrix transformation has been done using the well-known and computationally efficient corotational formulation. The corotational formulation separates rigid body modes from local deformation using, as reference, a single coordinate system that continuously translates and rotates with the element as the deformation proceeds.

It should be noted that the library of elements in OpenSees is not able to simulate both global and local buckling and, in light of this fact, the only damage that can be modeled is the strength damage. In order to model the global buckling in brace members of jacket part, a snapthrough model is used for brace representation with different end conditions. The utilized procedure defines an additional node in mid span of the brace and uses an initial imperfection equal to $1 / 100$ of brace length for this node. Utilizing this technique, which requires two force-based elements per brace member, along with using corotational formulation for coordinate transformation, buckling and postbuckling behavior of braces can be modeled accurately. The procedure of simulating the cyclic inelastic behavior of steel tubular members of JTOPs using fiber discretization technique together with nonlinear beam-column elements with distributed plasticity was investigated in previous research works of Honarvar et al. [7] and Asgarian et al. [34] and was compared to experimental results.

In this paper, in addition to the aforementioned provisions for modeling buckling and postbuckling behavior of braces, the possible failure due to low-cycle fatigue has also been considered in the developed numerical model. In a material model capable of simulating low-cycle fatigue in OpenSees software (Mazzoni et al. [31] and Uriz and Mahin [35]), once the fatigue life of the material exhausts and reaches a damage level of unity, the load carrying capacity of the material becomes zero, and this leads to a more realistic estimation of the global collapse of the structure. This fatigue material uses a modified rainflow cycle counting algorithm to accumulate damage in a material using Miner's Rule (Uriz and Mahin [35]). In the absence of experimental data for low-cycle fatigue tests of tubular sections, and due to the resemblance between tubular sections and box sections of the reported experimental data in Uriz and Mahin's work with the similar end conditions as is the case here, the $\varepsilon_{0}$-value of strain at which one cycle will cause failure-is considered to be equal to 0.095 for brace fatigue material. This value was obtained for a low-cycle fatigue test of a pinned member with box section under axial loading. It should be noted that, according to the test results reported in [35], the type of loading and end connections seems to play a more significant role than section type in determining the $\varepsilon_{0}$ value. Therefore, it may be interpreted that this value is a reasonable value for jacket brace member fatigue material. The material also has the ability to trigger failure based on a maximum or minimum strain, which is not related to the low-cycle fatigue phenomenon. For leg and pile members, due to the absence of experimental data to determine fatigue parameters, the lower bound conservative maximum ultimate strain values of 0.12 and 0.1 are considered, respectively. Therefore, the fatigue features are not utilized for these members. It is advantageous to emphasize that the aim of using fatigue material in this study is to prevent the estimation of the ultimate collapse capacity of a structure so as not to get values higher than realistic values.

The Beam on Nonlinear Winkler Foundation (BNWF) method also known as p-y approach is utilized in order to simulate soil-pile-superstructure interactions. In this method, the pile is modeled as beam elements while the surrounding soil is modeled using continuously nonlinear springs and dashpots. The soil nonlinearity is modeled using nonlinear springs whose parameters are determined analytically by defining stiffness and strength parameters. The dashpots, placed in series or parallel with the nonlinear springs, account for energy loss due to radiation damping under dynamic loading conditions. The force displacement behavior of nonlinear springs has been back calculated from the results of well instrumented pile lateral load tests in different soil conditions. Herein, soil lateral spring nonlinear behavior was modeled using the Pysimplel uniaxial material incorporated in OpenSees by Boulanger et al. [36]. The nonlinear $\mathrm{p}-\mathrm{y}$ behavior is conceptualized as consisting of elastic $\left(\mathrm{p}-\mathrm{y}^{\mathrm{e}}\right)$, plastic $\left(\mathrm{p}-\mathrm{y}^{\mathrm{p}}\right)$, and gap $\left(\mathrm{p}-\mathrm{y}^{\mathrm{g}}\right)$ components in series. A radiation damping dashpot is placed in parallel with the elastic element. The gap component itself is composed of a nonlinear closure spring $\left(\mathrm{p}^{\mathrm{c}}-\mathrm{y}^{\mathrm{g}}\right)$ in parallel with a nonlinear drag spring $\left(\mathrm{p}^{\mathrm{c}}-\mathrm{y}^{\mathrm{g}}\right)$. The constitutive behavior of Pysimple1 material for clay was based upon Matlock's relations of soft clay for static loading condition. API [30] recommended p-y backbone relation for drained sand is approximated by Pysimplel material for modeling of cohesionless soil. Boulanger et al. [37] showed that the resulting p-y curves based on the formulation of Pysimplel material for both clay and sandy soils match API p-y curves within a few percents over the entire range of $y$.

Instead of using common site response programs, this study uses the geotechnical capabilities of OpenSees to compute free-field response of soil layers. The response of soil profile is analyzed utilizing a combination of Pressure Independent Material for clay and Pressure Dependent Material for dense sand along with solid-fluid fully coupled quadUp elements of OpenSees. The pressure sensitive material stressstrain behavior is based upon one of the most robust constitutive models within the general framework of multisurface plasticity (Yang et al. [38]), which is capable of reliably analyzing flow failure type liquefaction and cyclic mobility 
scenarios. The characteristics of soil in different layers are input to the model including soil profile height, density of every soil layer, shear wave velocity of soil, undrained shear strength of soil $\left(C_{u}\right)$, soil shear modulus reduction curve $\left(G / G_{\max }\right)$, the location of free water, and bedrock characteristics and ground motion records at bedrock. It should be emphasized that, in order to take into account the hardening due to strain rate effects in near-fault earthquake ground motions, the upper bound soil characteristics derived from experimental data and tabulated in Table 2 are used for the analyses. Then, displacement time histories computed from the free-filed site response are exerted on the fixed nodes of $\mathrm{p}$ $y$ elements as the input ground motion excitation. Therefore, for dynamic analysis of soil-pile-structure system in the created numerical model, a number of ground motion time history records are applied simultaneously to the pile foundation at different soil elevations. The procedures of computing free-field soil response using the finite element model on the basis of geotechnical material and elements of OpenSees and also the procedure of the soil-pile-superstructure interaction modeling using this software are verified to experimental tests in a previous work of third author [39] and Assareh and Asgarian [18].

\section{Nonlinear Dynamic Analysis Results}

5.1. Definition of Considered IM and EDP. From the definition of IDA, a 2D IDA curve is a plot of an Engineering Demand Parameter (EDP) obtained from an IDA analysis versus an intensity measure (IM) that characterize the applied scaled accelerogram. Therefore, the fundamental step in IDA analysis is the determination of the IM and EDP. The IM is a quantity that represents the intensity of ground motion and is a measure of the strength of the applied earthquake force. In order to be able to scale the amplitude of the ground motion accelerogram with a scale factor in such a way that the intensity of the scaled accelerogram can be characterized with a quantity, the IM should be scalable. Many scalable quantities have been proposed to be considered to be IM among which the Peak Ground Acceleration (PGA) and the $5 \%$ damped pseudo spectral acceleration at the structure fundamental period $\left(S_{a}\left(T_{1}, 5 \%\right)\right)$ are examples of commonly used IMs. It was found that $S_{a}\left(T_{1}, 5 \%\right)$ is more effective due to its structure-dependent characteristics, compared to PGA, which is totally site-dependent. Knowing the shortcomings of $S_{a}\left(T_{1}, 5 \%\right)$ such as the lack of consideration of higher modes effects due to its simplicity over other advanced IMs, this IM is used as the preferred one in the current study.

On the other hand, EDP characterizes the response of the structure under investigation subjected to a prescribed seismic loading. In other words, EDP represents the output of the corresponding nonlinear dynamic analysis. It should be specified properly considering the characteristics of the structural system under investigation. In the case of urban buildings, the possible choices could be maximum base shear, peak storey ductility, peak roof drift ratio, and maximum peak interstorey drift ratio. Considering the fact that foundation rotations are negligible in buildings, the most suitable
EDP is maximum peak interstorey drift ratio, which is satisfactorily related to structural damage. For offshore platforms, the EDP should be selected based on the type of platform and the platform modes of failure. Jacket Type Offshore Platform is a multipart multienvironment structure consisting of two main parts (regardless of the deck equipment above water level), the jacket part above mud line and the piles driven into the soil. Consequently, the displacement of the deck is related to the behavior of the jacket and pile parts. In the well-head jacket platforms, the deck equipment is very expensive in comparison with other parts such as jacket and pile individually. Therefore, any proposed EDP should monitor the interstorey drift ratio as well as the displacement of the deck, and since this displacement is the consequence of brace buckling in the jacket and pile nonlinearity, the candidate EDP should take into consideration these two drift ratios as well. To this end, peak drift ratio from mud line up to deck level can be used in order to account for jacket interstorey drift ratio as well as pile foundation failure in most geotechnical conditions. This EDP is on the basis of the fact that the upper soil layers, a few meters beneath the mud line, are weaker than deeper soil layers, which leads to the more nonlinear behavior of pile in top region than the lower elements of pile. By scaling up the records and imposing much more severe seismic forces on the platform, the pile gradually fails and plastic hinges are formed. It may be concluded that the creation of these hinges causes rigid body rotation of the jacket part. Since this proposed peak drift ratio comprise of rigid body rotation of jacket and drift ratios due to brace buckling; in some cases, this special drift ratio could be considered to be the appropriate EDP for the well-head offshore platforms. However, this EDP is only effective when just one plastic hinge is formed in the pile and the remaining part of the platform rotates around this hinge. Consequently, this EDP loses its effectiveness in other failure modes of well-head platforms including shear mechanism of response, where two plastic hinges are formed in the upper part of the pile foundation. Vamvatsikos and Cornell [17] stated that in structures that have several collapse modes, such as the one treated in this paper, it is advantageous to detect the structural response with separate EDPs for each individual mode. Based on this recommendation, maximum interstorey drift ratio for the jacket part and maximum storey-like drift ratio per unit length of pile for the pile foundation are utilized as considered EDPs.

5.2. Sample Original Platform Incremental Dynamic Analysis. Depicted in Figure 4(a) is the individual IDA curve of record number 4 for the original platform. The vertical axis in this figure is the $5 \%$ damped spectral displacement at structure's first mode period $\operatorname{Sde}\left(T_{1}, 5 \%\right)$. Sde is analogous to pseudo spectral acceleration since Sde is equal to pseudo spectral acceleration divided by the square of $w$, where $w$ is the first mode angular frequency of the structure. The horizontal axis in this figure is maximum storey-like drift ratio per unit length of pile. It should be noted that the term "drift ratio" in the horizontal axis label in this figure and all the following figures is illustrated for brevity as "drift." As it is noticed from this figure, the IDA curve is monotonic and 


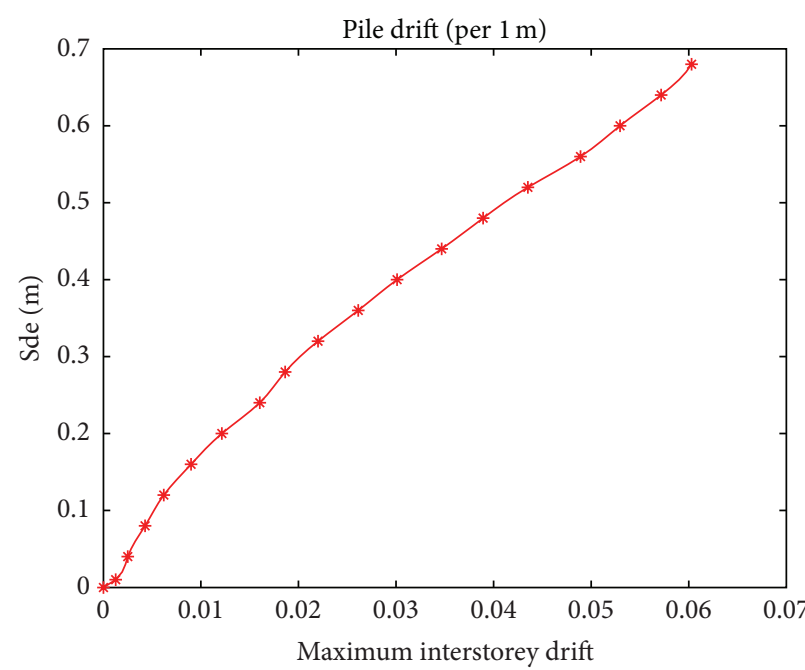

(a) Storey-like pile drift ratio per unit length of pile

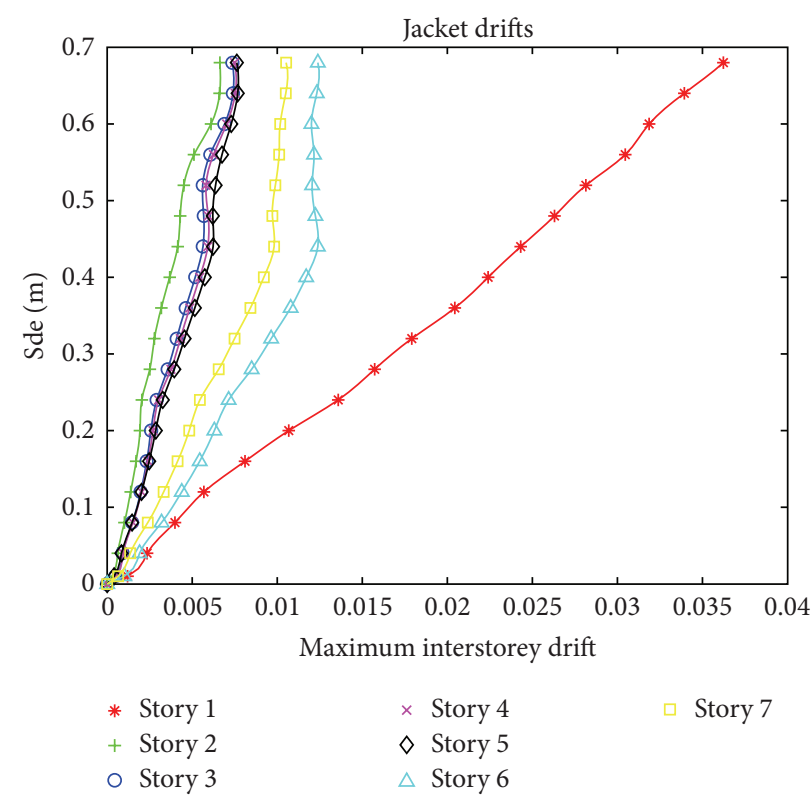

(b) Jacket storey drift ratios

FIgURE 4: IDA curves of record number 4 for original platform.

is gradually degraded towards collapse without any back and forth twisting behavior usually observed in IDA curves of simple urban buildings. Although in other record result illustrations, as will be shown in the following figures, a low level of weaving behavior is observed, compared to urban structures, a more monotonic response is obtained in this figure. The reason for this monotonic behavior is the concentration of nonlinearity in the upper parts of the pile in almost all records as opposed to building structures where stiffness and mass along various elevations of structure are distributed more uniformly, and it is likely for all storeys to experience some levels of nonlinearity. Indeed, the earlier creation of plastic hinges in the upper part of the pile foundation causes this region of pile to work as a weak storey and, therefore, prevents other parts of the platform to meet at a nonlinear range of response. This leads to a shear mechanism of response in pile foundation where two plastic hinges (in each pile) are formed at mud line level and a few $(4-6 \mathrm{~m})$ meters beneath the mud line. The outcome is that the jacket part remains without rotations. This mechanism of response will be discussed in details by presenting IDA curves of various jacket storeys. Illustrated in Figure 4(b) are the IDA curves of different storeys of the jacket part of the platform. The storey level 1 represents from the mud line up to the first horizontal framing of the jacket at an elevation of $71 \mathrm{~m}$, and its response behavior is related closely to pile foundation. Actually, the braced storeys of the jacket start from storey level 2 in this figure. As can be observed from this figure, the EDPs of all braced storeys are constant at various levels of intensity measure of input ground motion record, implying that the jacket remained unrotated in all scales of input ground motion record. Since storeys 6 and 7 are unbraced and only the portal behavior resists lateral loading,

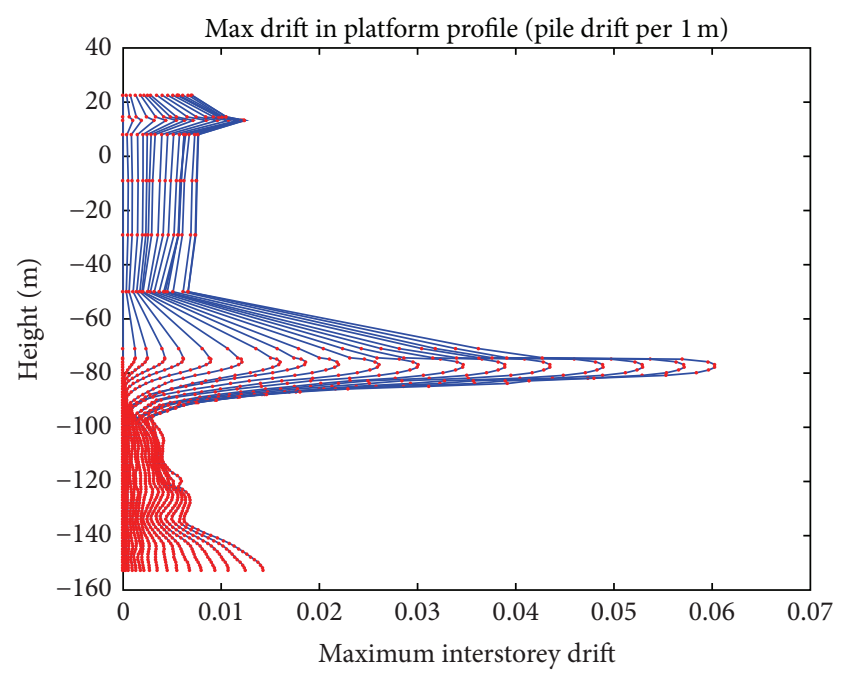

FIGURE 5: The profile of maximum drift ratio in different elevations of platform from the pile tip up to the deck level.

the exhibited EDPs in these storeys are slightly higher than other braced storeys of jacket.

Figure 5 illustrates the profile of the maximum drift ratio at different elevations of the platform from the pile tip up to the deck level. Results show much greater drift ratios at 15 meter below mud line in comparison with other levels. This observation is due to the weak strength of the soil exactly beneath the seabed as mentioned in previous discussions and, more importantly, due to the weakness of the pile foundation relative to the jacket part. It is apparent in this figure that the EDPs of different storeys of jacket are approximately constant 


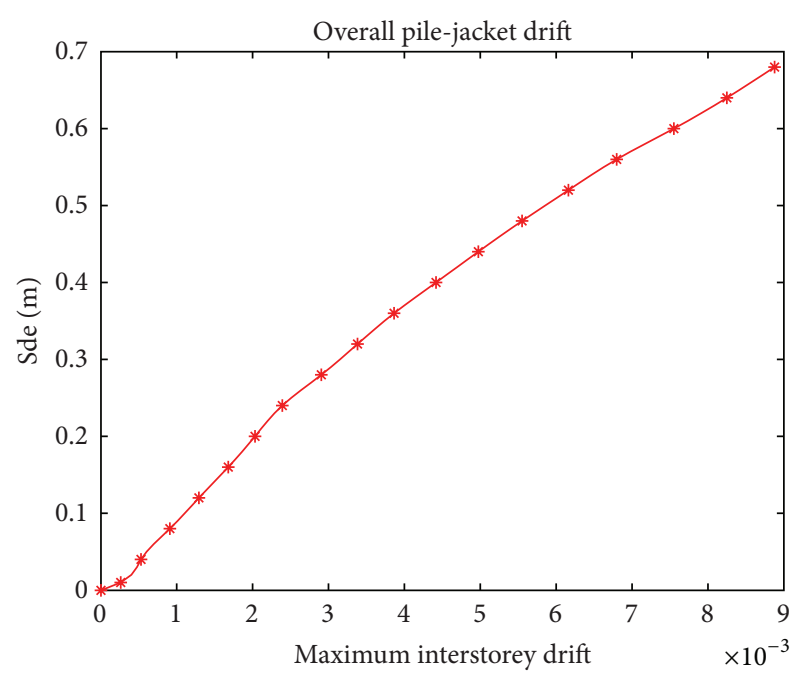

Figure 6: The overall drift ratio of the original platform from the pile tip up to the deck level.

at a specified intensity measure being an evidence of straight positioning of the jacket part during response to earthquake loading. Figure 6 shows the overall drift ratio of the platform from pile tip up to deck level.

It can be inferred from the consistency between this figure and Figure 4(a) that the failure mechanism of the whole platform originates from pile nonlinearity rather than from the response of any other parts of the platform. It should be noted that, in this special record, the drift ratios in the lower part of the pile foundation (the lowest $15 \mathrm{~m}$ of pile) are negligible compared to the upper parts and, therefore, the overall pile drift ratio from the pile tip up to the mud line is consistent with the maximum storey-like drift ratio per unit length of the pile, while, in some of the records, the drift ratios in these parts are considerable, which makes overall pile drift ratio inconsistent with maximum storey-like drift ratio per unit length of the pile. However, in all records, the jacket response is the same as this record and only the pile foundation shows nonlinear range of deformation.

Depicted in Figures 7(a) and 7(b) are results of IDA curve of record number 17 in terms of maximum storey-like drift ratio per unit length of pile and the overall drift ratio of platform from the pile tip up to the deck level, respectively. In Figure 7(a), the EDP increases at a constant rate with increase in the intensity of earthquake up to Sde equal to $0.6 \mathrm{~m}$. Subsequently, from Sde ranging between 0.6 and $0.9 \mathrm{~m}$, the IDA curve "hardens," having a local slope higher than that of the first monotonic part. In this range of response, the structure experiences the deceleration of the rate of EDP accumulation, which leads to a stop in EDP accumulation or even a reversal. Then, the IDA curve starts softening again showing greater range of EDP accumulation as IM increases. Finally, the ultimate strength of the pile fiber material is reached, and as a consequence the platform reaches its final capacity and experiences global dynamic instability. Comparing Figures $7(a)$ and 7(b), one can recognize a fairly considerable consistency between IDA curves in terms of maximum storey-like drift ratio per unit length of pile and the overall drift ratio of the platform from the pile tip up to the deck level implying the predominating of pile nonlinearity on platform mechanism of response.

\subsection{Pile Strengthened Platform Incremental Dynamic Analysis.} Figure 8 illustrates the IDA curves of different storeys of the jacket part of the Pile Strengthened Platform (PSP HE2) subjected to record number 4 . The storey nomination is similar to the aforesaid original platform. Comparing this figure with Figure 4, the first important finding is that the ultimate strength of the platform is enhanced to a high degree. The original platform meets its final capacity at an IM level equal to $0.68 \mathrm{~m}$, as mentioned previously after the formation of plastic hinges at the upper parts of the pile foundation. On the other hand, the PSF HE2 platform reaches its ultimate capacity at an IM level of $4.3 \mathrm{~m}$, where the braces of storey level 2 buckles, and then the portal behavior of the leg at this elevation is activated. Finally, the platform falls down after the creation of plastic hinges at an elevation of $50 \mathrm{~m}$. Additionally, from Figure 8, it is observed that a considerable jump occurs in the EDP of storey level 2, which is the first braced storey of the platform. The reason for this abrupt change in EDP is that the ultimate strength of both compression and tension brace materials at storey level 2 of this IM level is reached and that the load carrying capacity of the braces becomes zero. This abrupt change in IDA slope is a sign of the low redundancy of this Platform model after first member failure. In all the subsequent scale steps of IDA curve, only the portal behavior resists lateral loading until the ultimate strength of the leg material is reached and the whole platform collapses.

Figure 9 illustrates the profile of the maximum drift ratio at different elevations of the platform from the pile tip up to the deck level. This figure illustrates various scale steps of IDA analysis of record number 4 . Similar to the analysis results of the original platform, the analysis results of PSP platform show much greater drift ratios at 15 meter below the mud line in comparison with other levels. It should be added that even though the storey braces buckle in this model, contrary to original platform model, and the collapse of the platform results from the jacket leg failure, the pile foundation still exhibits high nonlinear response emphasizing the influence of the pile foundation on platform response. As opposed to the original platform response, the drift ratios at elevation of $50 \mathrm{~m}$ in Figure 9 show abrupt increase in seven final scale steps of analysis.

The proportional distribution of nonlinear behavior is the key factor in the enhancement of the ultimate strength of the platform. Considering the results of PSP HE2 platform analysis, it can be inferred that a slight change in the strength of the pile foundation makes the stiffness and strength of the pile foundation more proportional to the stiffness and strength of the jacket part, and this leads to uniform distribution of damage or nonlinear behavior in both jacket and pile foundation. Reducing the stiffness of the jacket part in the original platform also makes the strength of these two parts more proportional and leads to similar results. To demonstrate this observation in more details, the maximum stress-strain response of the pile foundation and the legs at 


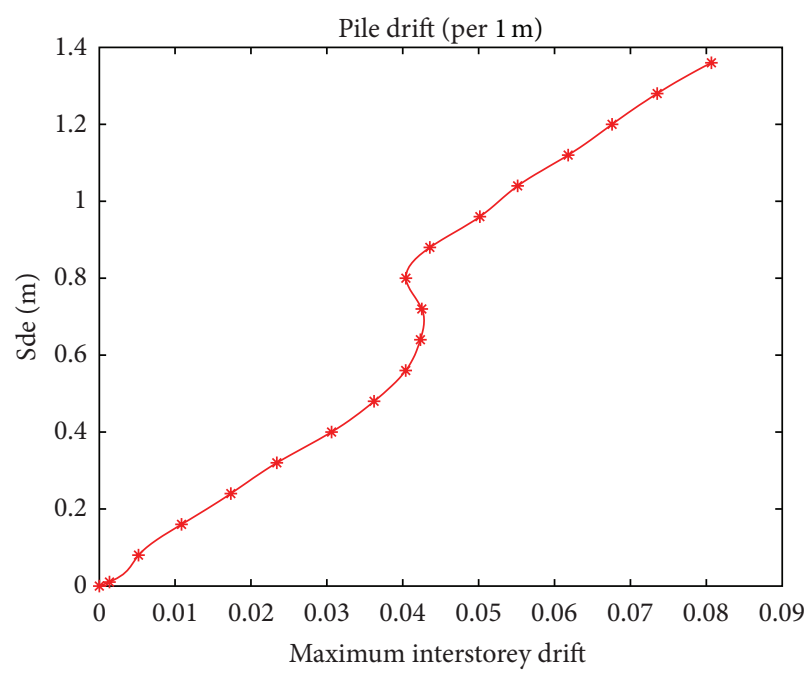

(a) Storey-like pile drift ratio per unit length of pile

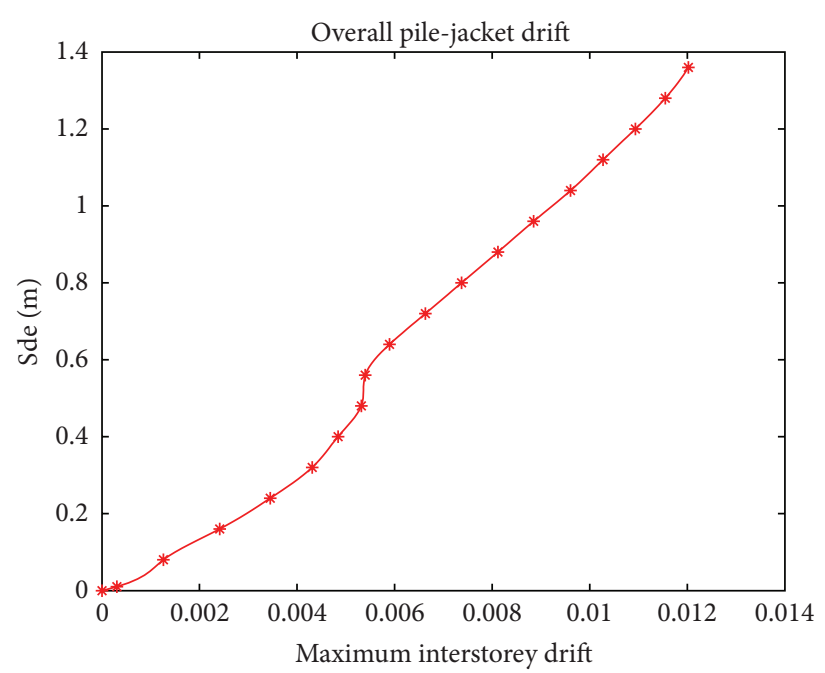

(b) Overall drift ratio from pile tip up to deck level

FIgURE 7: IDA curves of record number 17 for original platform.

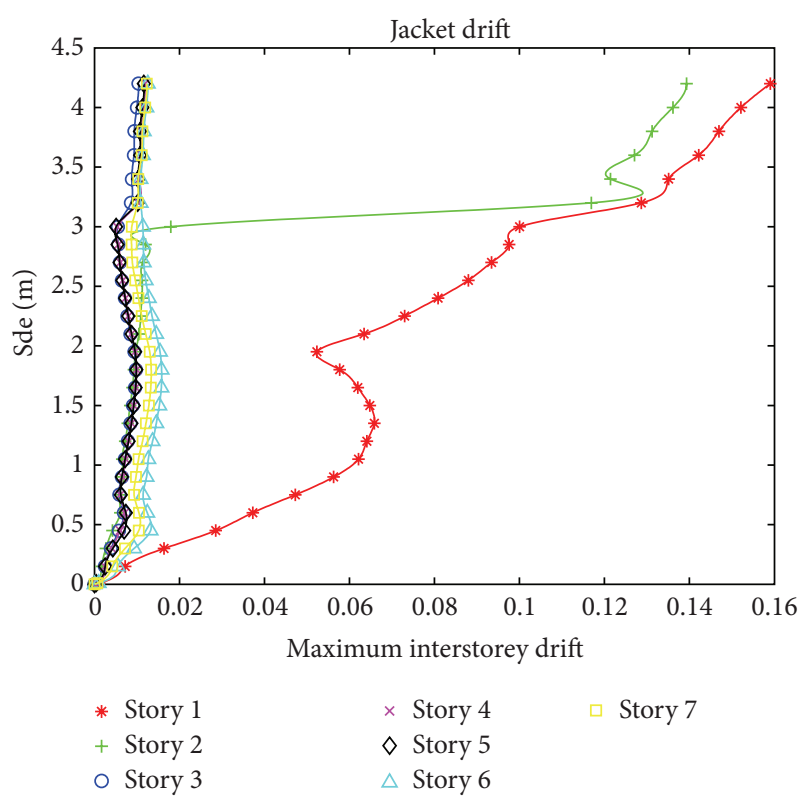

FIGURE 8: IDA curves of different storeys of the jacket part of PSP HE2 Platform.

storey level 2 are postprocessed and consequently, as depicted in Figure 10, the IDA curve of storey level 2 subjected to record number 4 is separated into three distinct parts.

In part one, the platform responds in the same manner as the original platform where the braces have not buckled and the nonlinearity is concentrated in the pile foundation. In part two, the braces buckle and the loads in the platform elements are redistributed, which leads to a sudden drop in the stressstrain demands of the pile foundation and an increase in the leg of the jacket stress-strain demands. Finally, in part three, tearing in braces due to high inelastic demands occurs and the load carrying capacity of the braces becomes zero.

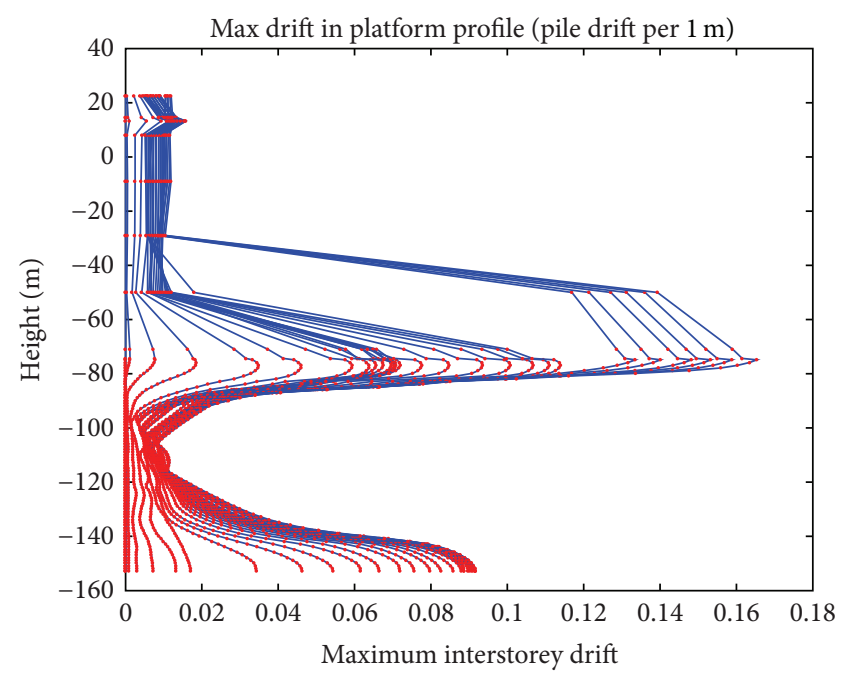

FIgURE 9: The profile of the maximum drift ratio in different elevations of the platform from the pile tip up to the deck level.

The omission of braces forces the legs to absorb the whole shear loads imposed on the jacket by earthquake ground motion. It is advantageous to note that, while in parts 2 and 3 the nonlinear demands in the pile foundation decreases comparatively to part 1 , it still experiences high excursions of inelastic deformations.

A special type of IDA response is observed in this platform model analysis for some records of ground motion, which has not been reported previously for urban buildings. Illustrated in Figures 11(a) and 11(b) are the record number 17 IDA curves of different storeys of the jacket part of the platform and the pile foundation drift ratio per unit length of the pile, respectively. As shown in these figures, the EDPs increase monotonically up to some IM levels, and then, with an increase in IM, no EDP accumulation occurs and the IDA 


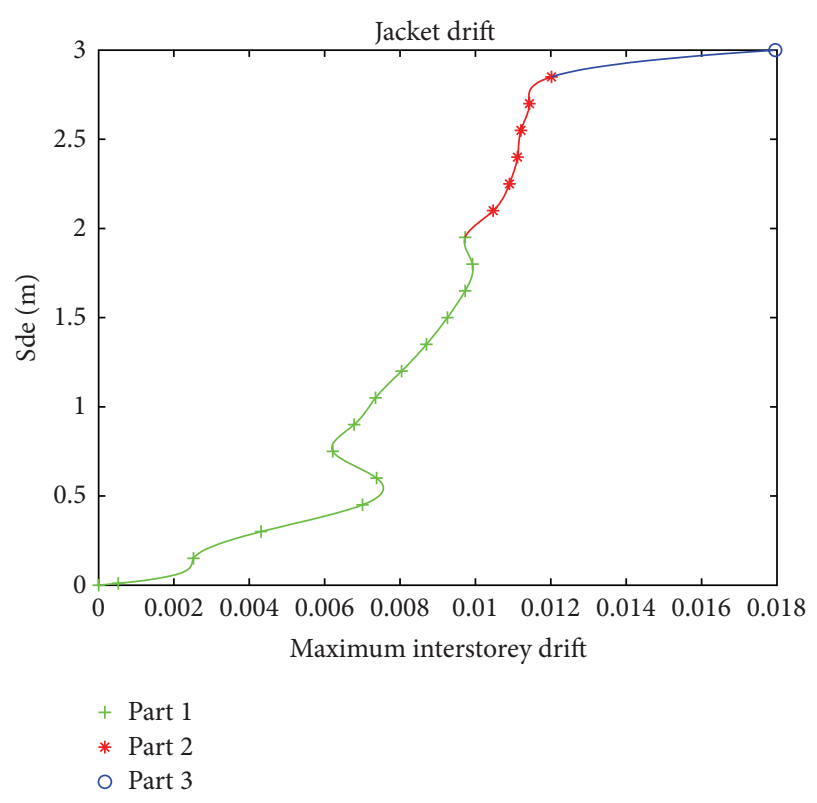

Figure 10: The IDA curve of storey level 2.

curves become approximately vertical. As a consequence, the platform does not meet its final capacity, at least in the expected intensity range of probable earthquakes in the engineering field; in other words, collapse does not occur. The reason behind this phenomenon is that, in some scales of these records, the input ground motion is so strong that it drives the soil to its final capacity and because of soil strain softening, no more load is transferred to the platform structural part. From another stand point, in high levels of seismic intensity, the high nonlinearity in the soil profile acts as a source of damping and therefor reduces the seismic risk of the platform.

5.4. Jacket-Softened Platform Incremental Dynamic Analysis. With the jacket becoming relatively more flexible, it is anticipated that the jacket part of the platform contributes more effectively to the platform nonlinear response characteristics and, similarly, to the input seismic energy dissipation mechanism. Therefore, it makes the strength and stiffness distributed more uniformly in full platform height. To clarify the contribution of this on the dynamic behavior, some illustrations along with their discussion are presented in order to fully disclose the aspects of flexible jacket phenomenon. In accordance with previous sections, the individual IDA curves of record number 4 for different storeys of the jacket part are demonstrated in Figure 12. By examining this figure critically, it is noticed that different storeys of the platform contribute to its nonlinear range of deformation in the whole ranges of IM. This irregularity is even more critical in other records as an inherent aspect of flexible jacket response.

The storey level 1 is the first section of the jacket to show relatively notable inelastic response even in low levels of earthquake intensity. This fact seems to hold for all other records studied in this work. As stated previously, the response of this storey is representative of the pile drift demands in the upper part of the pile foundation. Due to space limitation, they are not shown here. At two IM scale steps between $0.6 \mathrm{~m}$ and $0.9 \mathrm{~m}$ in this figure, the storey levels 3 and 4 are the first braced storeys to buckle leading to a sudden jump in IDA results. This phenomenon is attributed to the fact that the higher modes of vibration contribute significantly to the seismic interstorey drift response $(\theta)$ at least in the elastic range or low levels of inelastic response, shifting the $\theta_{\max }$ drift to higher storeys. This is the case in low or intermediate ranges of IM for all 10 records studied here.

Analogous to PS platform, occurring of brace buckling in jacket storeys reduces the deformation demands in the pile foundation (see storey level $1 \mathrm{drift}$ at IM values ranging from $0.6 \mathrm{~m}$ to $0.9 \mathrm{~m}$ in Figure 12 ). At higher intensity levels, the inelastic excursions are gradually transferred to lower storeys of jacket (storey levels 2 and 3). These inelastic demands commence by brace buckling at intermediate ranges of IM, and as the intensity of earthquake increases, the contribution of portal resistance in the legs plays a more paramount role in jacket dynamic resistance. Illustrated in Figure 13 is the profile of maximum drift ration at different elevations of platform from the pile tip up to the deck level in various IDA scale steps. As it is seen, the lower storeys of jacket show high nonlinear behavior in many scale steps. Furthermore, exempting some lower IM levels, the braces at storey level 5 (elevation between $-8 \mathrm{~m}$ up to $9 \mathrm{~m}$ ) buckle in all other IM levels participating in the jacket energy dissipation mechanism. This observation can be simply verified by comparing Figures 13 and 9.

Figure 14 depicts the IDA curves in terms of the overall drift ratio of the pile from the pile tip up to the mud line level, overall drift of jacket from the mud line level up to the deck level, and overall general drift of the platform from the pile tip in the lowest elevation up to the deck level at the top most elevation. As it is observed, there is a mild consistency between overall pile drift and pile drift per unit length of pile associated with storey level 1 drift in Figure 12, or even inconsistency in higher IM levels. Furthermore, there is a close relationship between maximum interstorey drift over all storeys (see Figure 12), jacket overall drift, and whole pile and jacket overall drift in Figure 14, implying the domination of jacket interstorey response on the whole platform displacement demands.

In order to emphasize he effects of pulse-like records on the platform response, the IDA results of record number 17 is presented in Figure 15, which shows a surprising feature of response. As opposed to the two previous platform models behavior and results of most of the other records subjected to this model, the nonlinear mechanism of response at higher IM levels is concentrated in upper storeys of the jacket part. This is interpreted as the effect of the ratio of this record pulse period to fundamental period of the structure $\left(T_{p} / T_{s}\right.$ ratio), which seems to excite higher modes of response. In this case, as the structure behaves nonlinearly at high intensity levels and its effective modal periods lengthen, it is anticipated that the lengthened second mode of vibration of the structure coincides with the record pulse period $\left(T_{p} / T_{s^{2}}\right.$ ratio equal to unity), which causes larger response compared to the response of PS platform to record number 17. According to 


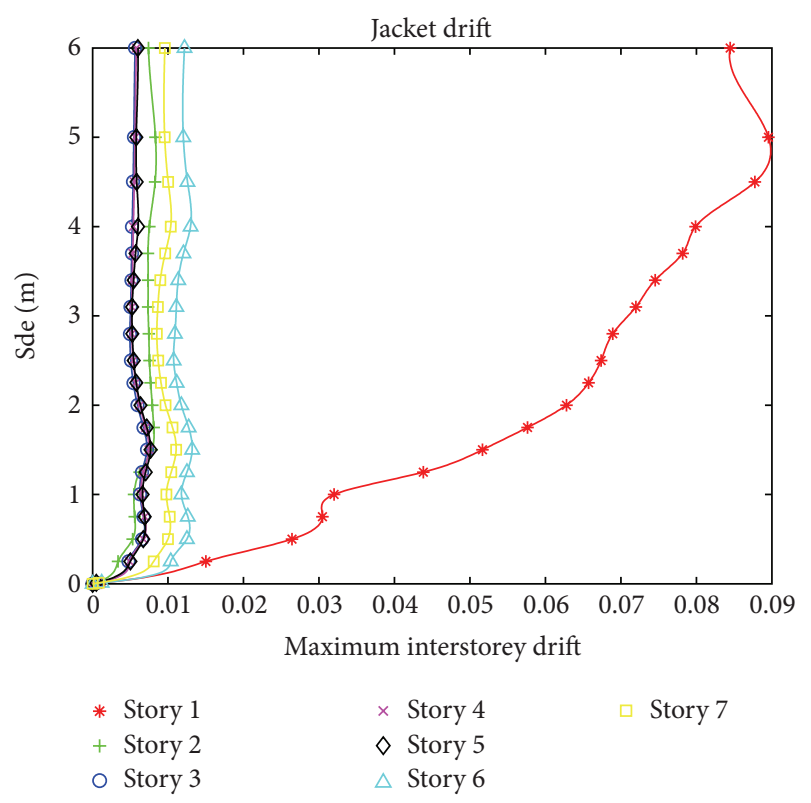

(a) Jacket storeys drift ratio

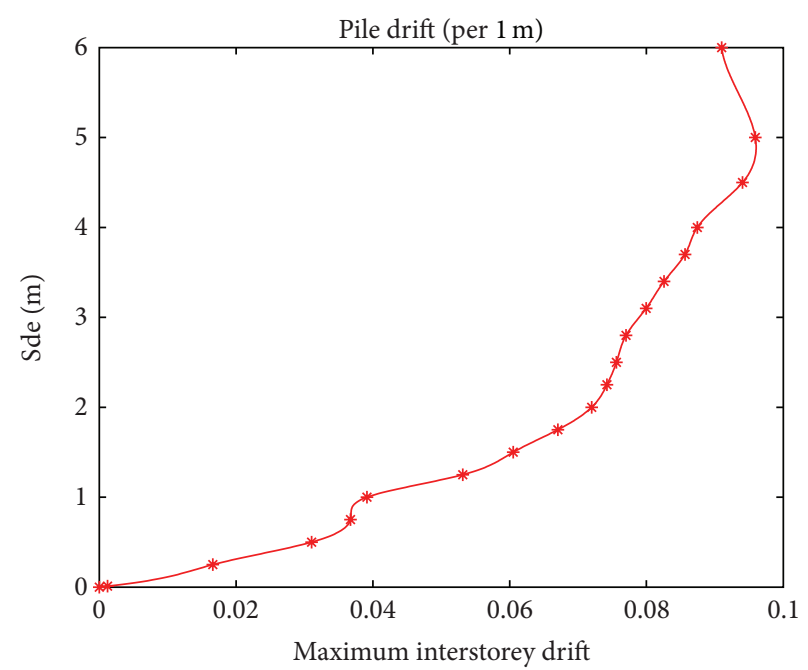

(b) Storey-like pile drift ratio per unit length of pile

FIGURE 11: IDA curves of PSP platform subjected to record number 17.

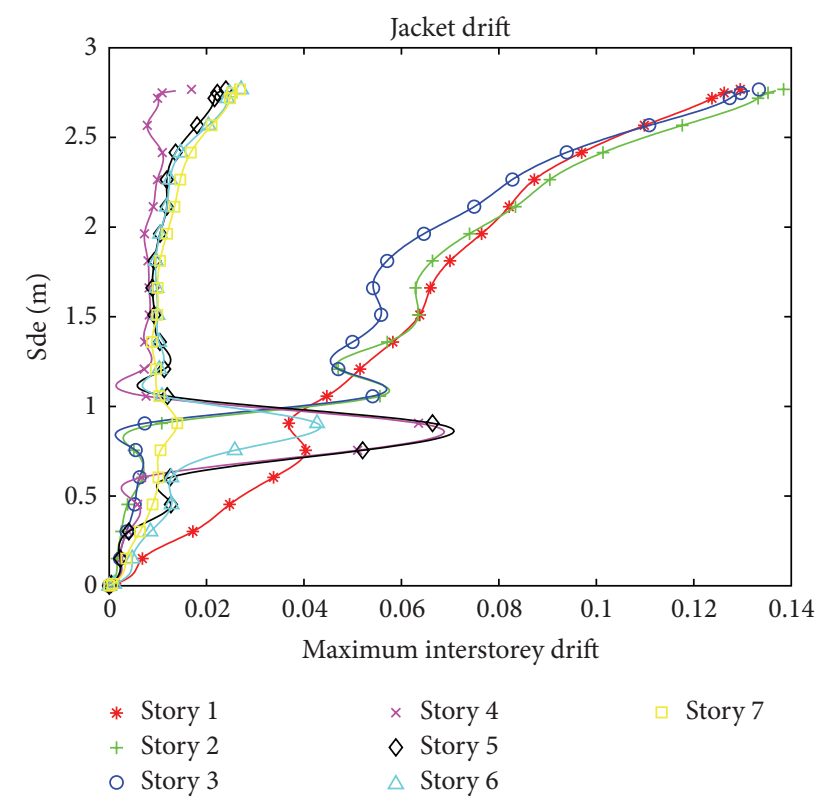

FIGURE 12: IDA curves of different stories of jacket part subjected to record number 4 .

Figure 15, it is advantageous to add that while the platform excites with its higher modes, the deformation demands in the pile foundation are significantly reduced. This can be proved by simply comparing the pile drifts (storey level 1 drift) in this figure and other record results.

5.5. Sample Platform Models Pushover Analysis. The purpose of pushover analysis is to estimate the expected performance of a structural system by estimating its strength and

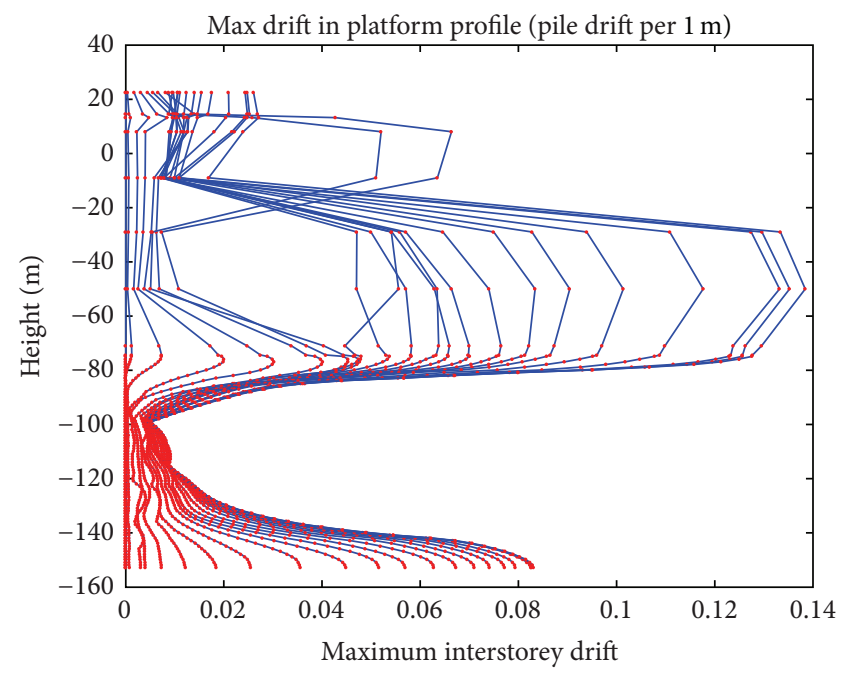

FIGURE 13: The profile of maximum drift ratio in different elevations of platform from pile tip up to deck level.

deformation demands in future earthquakes by means of an incremental static inelastic analysis, which accounts in an approximate manner for the redistribution of internal forces occurring when the structure is subjected to inertia forces that can no longer be resisted within elastic range of behavior. In this part, in order to assess the applicability of this simple procedure and its comparison with final solution time history analysis, the pushover analysis has been carried out for the three platform structural models. The pushover pattern is selected based on a "first mode lateral load pattern" presented by Chopra and Goel [40]. A modification is applied to this pattern changing the power of the modal vector terms in 


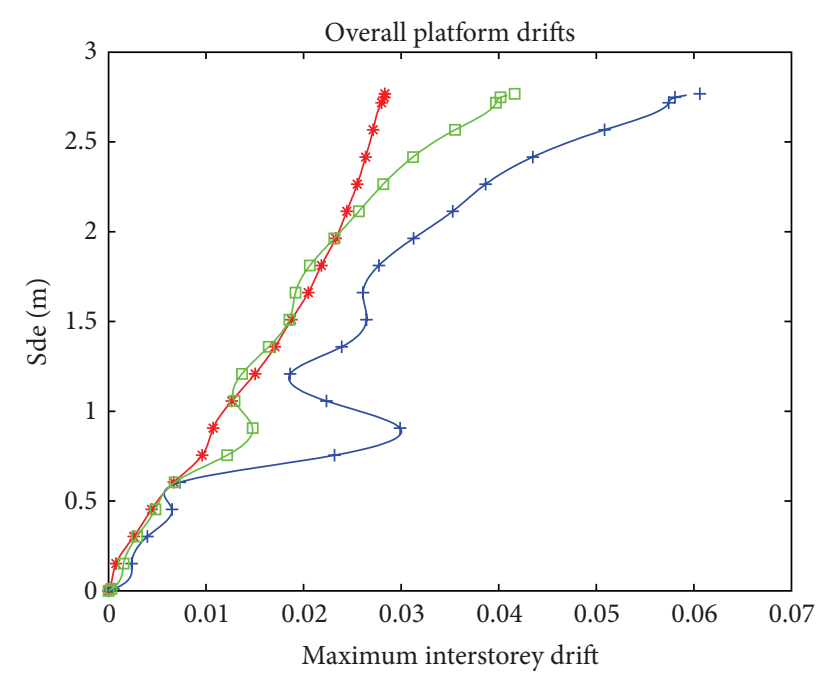

* Overall pile drift

+ Overall jacket drift

$\square$ Overall pile-jacket drift

FIGURE 14: The overall platform drift ratios.

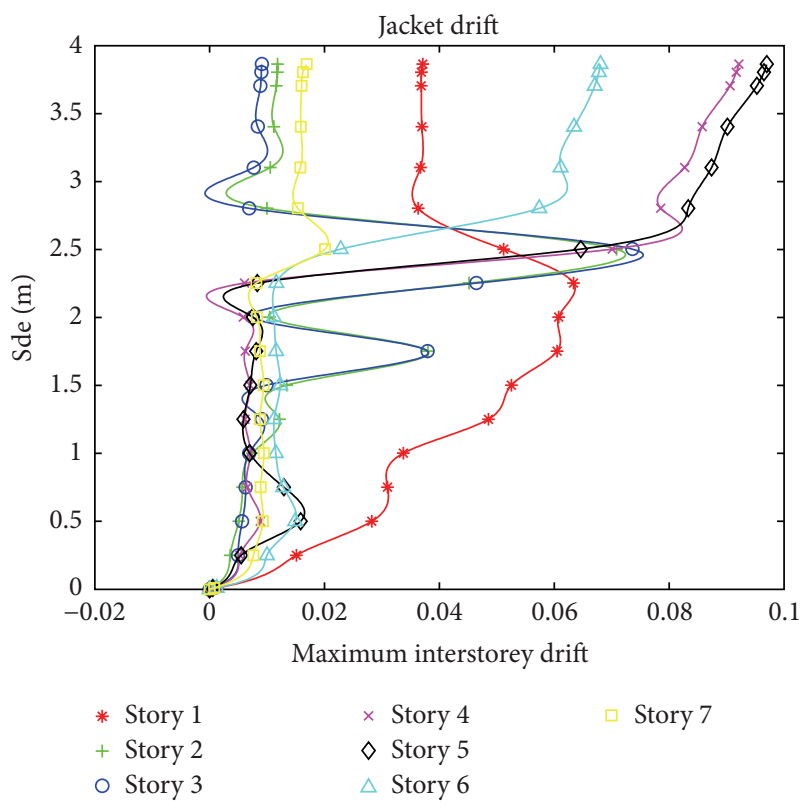

FIGURE 15: IDA curves of different storeys of jacket part subjected to record number 17.

pattern formulation from a value equal 1 to 0.4 . This modification makes the role of mass distribution more significant rather than the modal shape vectors role. Figure 16 depicts the resulting curves of the conducted pushover analysis of the three platform models. Results show that the pushover analysis can successfully predict the failure mechanism of the original platform models where two plastic hinges are formed at mud line level and a few $(4-6 \mathrm{~m})$ meters beneath the mud line, and, therefore, the jacket part remains without rotations. Finally, the global instability occurs when the pile material reaches its ultimate resistance.

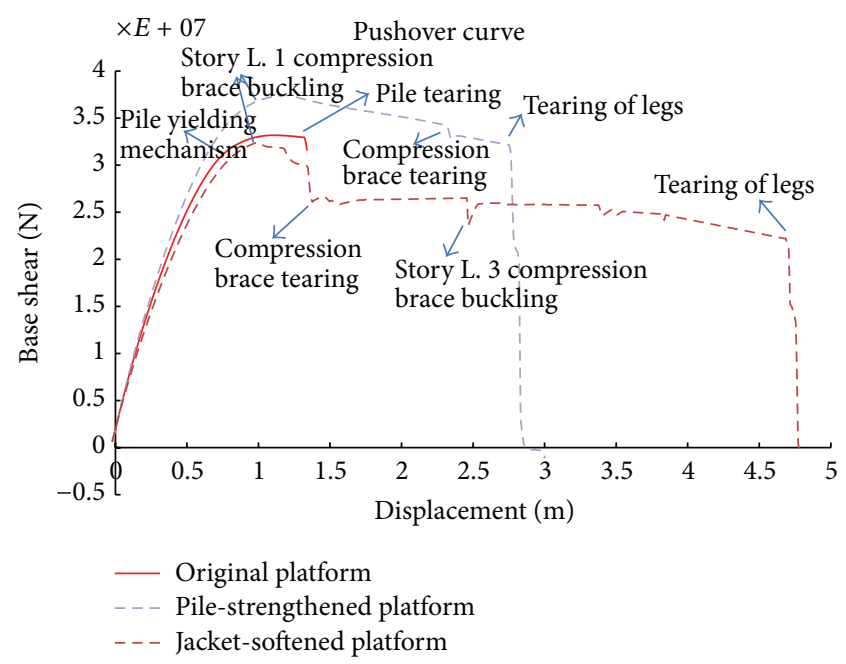

FIGURE 16: Sample well-head platforms pushover analysis curves.

In the case of PS platform, the jacket maximum load carrying capacity is enhanced relative to the original platform model, and a significant loss in platform lateral stiffness happens when the brace of storey level one buckles. This is followed by the tearing of compression brace and, finally, leg failure. There is a fairly good agreement between the observed failure mechanism of pushover analysis and the platform mechanism of failure within some of the earthquake time history analysis. In the case of flexible jacket model, the platform lateral stiffness and correspondingly the maximum lateral resistance are even lower than the original platform model due to flexible jacket concept. Herein, the softening behavior of the jacket is initiated by storey level 1 brace buckling and followed by tearing of brace and storey level 3 brace buckling, and, finally, leg failure leads to whole platform global instability. Although the pushover analysis could not predict the whole sequence of failure in this case, the general trend of failure is in agreement with IDA results.

Taking the area under the force-deformation curve of pushover curve as the potential energy dissipation capacity of the structure, according to Figure 16, it is clear that the ductility capacity of the structure has been significantly improved in the modified models compared to the original model.

\section{Multirecords IDA and Collapse Fragility Curves}

A single-record IDA analysis cannot fully capture the behavior that the platform may display in future ground motions. The IDA study can be highly dependent on the record under investigation; therefore, a sufficient number of records should be selected to cover the full range of responses. Herein, as stated in previous sections, a suit of 10 near-fault ground motions has been selected for IDA analysis. After applying all these records on the structure, multirecords IDA can be obtained. A representative multirecords IDA curve for original platform is illustrated in Figure 17. The EDP in this 


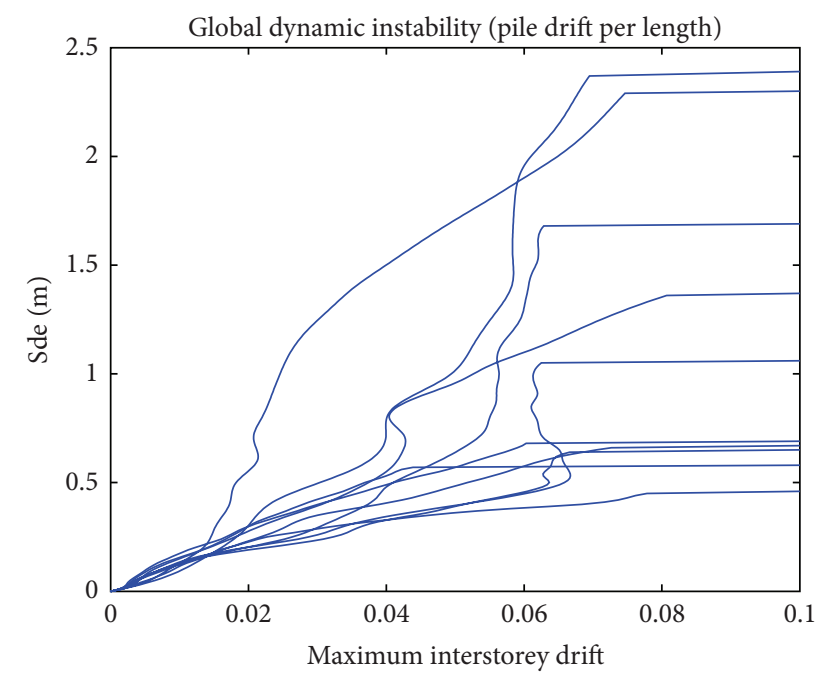

FIGURE 17: Multirecords IDA curve for original platform.

figure is in terms of storey-like pile drift ratio per unit length of pile, since the collapse in this platform model is the result of plastic hinge formation in pile foundation. Obviously, no apparent difference is seen when the intensity of seismic input is low but, as IM rises, differences appear to become significant. The variations in values of IM corresponding to flat lines (which represent collapse) indicate that the selected records excite the platform in different manners, and this is a remarkable sign of the suitability of the selected records in representing the randomness in future ground motions.

Multirecords IDA results of PSP HE2 platform are plotted in Figures 18(a) and 18(b) in terms of storey-like pile drift ratio per unit length of pile and jacket maximum interstorey drift ratios, respectively. Since the collapse does not originate from the pile foundation failure, the flat lines are not presented in Figure 18(a). As it is observed in this figure, in five records of record suit the individual IDA curve becomes approximately a vertical line, since in some scales of ground motion record the soil reaches its ultimate shear strength exhibiting a flow-type response. These vertical IDA curves can also be distinguished in IDA curves of jacket interstorey drift ratios as depicted in Figure 18(b).

From this figure, it is apparent that the interstorey drift ratios of jacket part show an abrupt increase in EDP for records that cause collapse in the structure. In three of the collapsed records, the platform experiences global dynamic instability slightly after this sudden change in platform stiffness implying relatively low redundancy of jacket structure. However, this is not the case for all records since, for two remaining records, the platform exhibits reserved strength after the aforesaid change in IDA slope. The later phenomenon is attributed to simultaneous brace buckling of both storey level 2 and level 3 implying the complicated modes of behavior of the platform when subjected to different records of various natures.

Illustrated in Figures 19(a) and 19(b) are multirecords IDA results of JS HE2 platform in terms of storey-like pile drift ratio per unit length of pile and jacket maximum interstorey drift ratios, respectively. Similarly, since the collapse does not originate from the pile foundation failure, the flat lines are not presented in Figure 19(a). In this platform model, in three records of the selected record suit, the platform does not meet global dynamic instability performance level in the expected ranges of IM. This is interpreted as the effects of soil softening behavior both in near field and in far field. However, in this model, the platform shows much more nonlinear behavior at higher IM levels than the PS HE2 platform model, and pure vertical lines are not observed in the ID curves of these records.

According to Figure 19(b), the concept of abrupt increase in the interstorey drift ratios of the jacket part is seen in almost all earthquake records considered here. This is attributed to the high flexibility of the jacket part of the platform. In this regard, independent of the nature of record, by scaling the ground motion record, at an IM level, a combination of storeys shows high excursions of EDP demands. It is advantageous to note that these abrupt changes in EDP are less significant comparatively to PS HE2 platform analysis results. Another remark that can be drawn from Figure 19(b) is that the platform exhibits a high level of reserve strength in the order of 2 to 6 times the intensity level that the aforementioned change in IDA slope took place. The main cause of this paramount reserve strength is the contribution of more than one storey to the inelastic demands of the jacket part within earthquake analysis.

The collapse limit state fragility curve is defined as the conditional probability of structural collapse for a given IM level. Collapse fragility curves relate ground motion intensity to the probability of collapse of structure. The probability of collapse at each intensity level is then computed as the fraction of ground motions that causes collapse at the considered intensity level. Naturally, the number of ground motions used at each intensity level influences the accuracy of this estimate. Depicted in Figure 20 are the collapse fragility curves of three platform models investigated in this study. Comparing the collapse fragility curves of these platforms, it can be inferred that the probability of collapse is highly reduced when the pile foundation of original platform is strengthened or, similarly, by softening the jacket part. This reduction in probability of collapse in the modified models of the original platform is mostly due to the uniform distribution of nonlinearity along the pile foundation and the jacket part and more importantly due to the effect of soil flow failure. An abnormal collapse fragility curve is obtained for these modified models where, for example, for PSP HE2 platform, from IM levels higher than $4.2 \mathrm{~m}$, five of the records do not drive the platform to its final capacity and, consequently, the probability of collapse does not reach to unity. The pulse periods of the records are shown as data labels in Figure 20. As it is obvious, the probability of collapse is directly related to pulse period of record. As the pulse period increases, the platform tends to experience collapse at lower levels of IM.

\section{Design Recommendations}

As stated in previous sections, the base case platform model investigated in this study is planned and designed based 


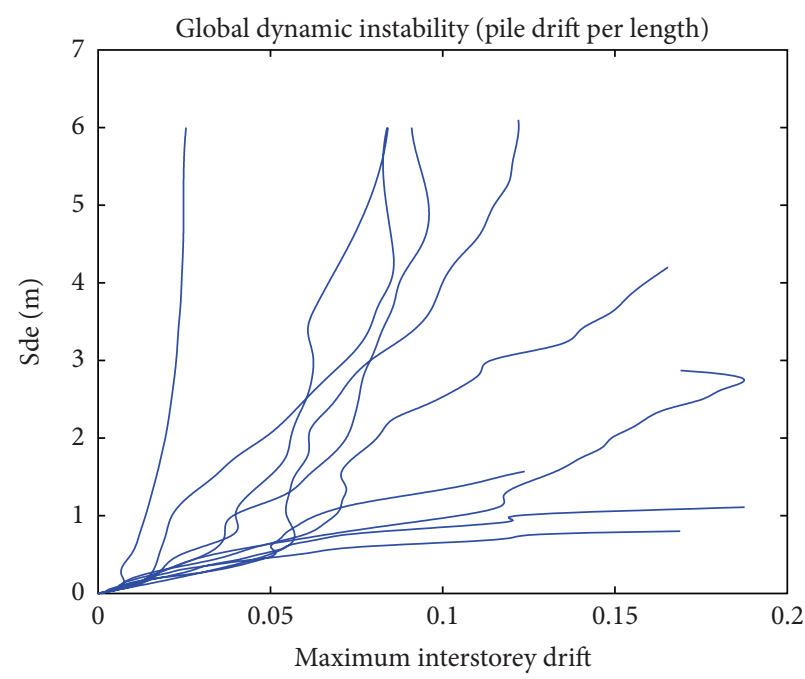

(a) Storey-like pile drift ratio per unit length of pile

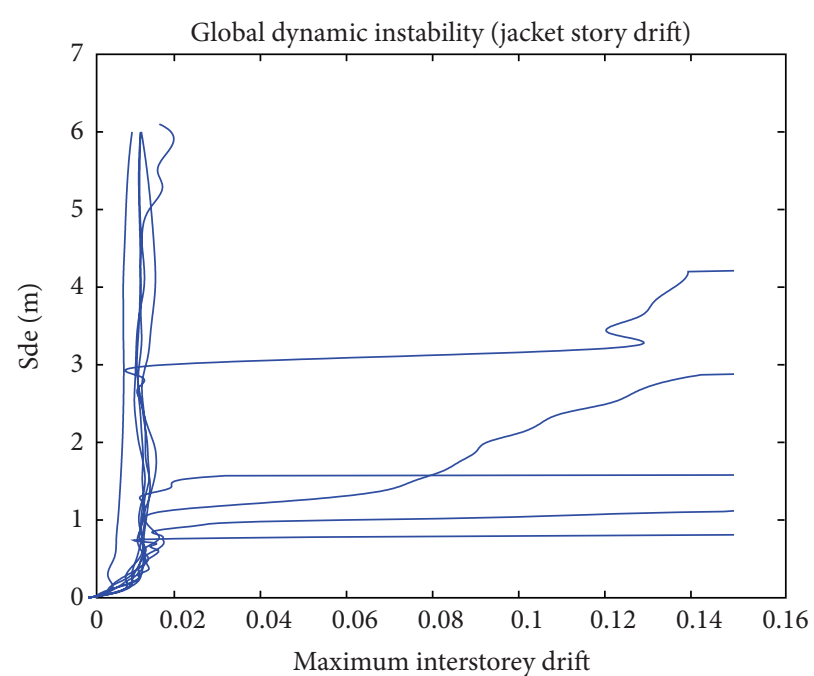

(b) Jacket maximum interstorey drift ratio

FIGURE 18: Multirecords IDA results of PSP HE2 platform.

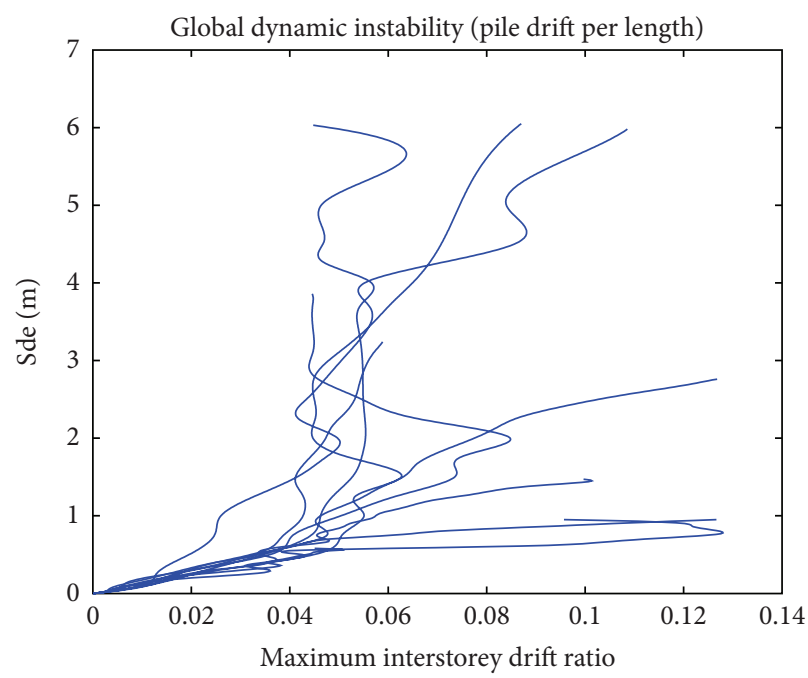

(a) Storey-like pile drift ratio per unit length of pile

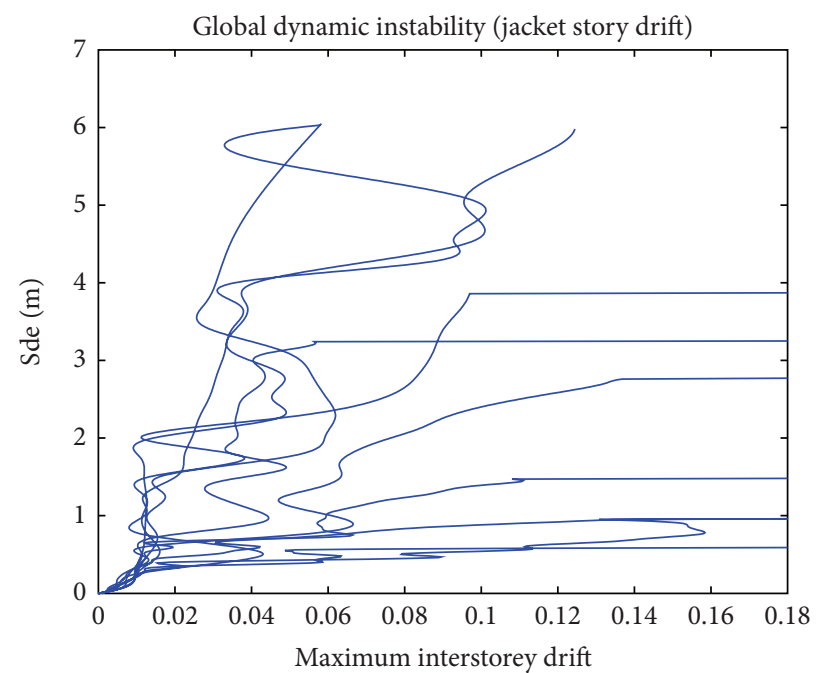

(b) Jacket maximum interstorey drift ratio

FIGURE 19: Multirecords IDA results of JS HE2 Platform.

on the basic requirements of API RP2A-WSD [30] recommendation, while the analysis in this study revealed a lack of optimum response during earthquake response history analysis. This does not mean that the platform does not meet the design environmental load conditions. The main idea behind this paper is to answer the following questions: What is the optimum response, or what should be taken into consideration, to achieve a better seismic response mainly near the ultimate strength performance level? The previous question leads to a subsequent question: What analysis procedures or tools should be utilized during the design process to ensure an optimum response? Based on the findings from this study, the following design recommendations are made:

(a) Although the pushover analysis is an evaluation process that is relatively simple, yet it can predict the essential features that significantly affect the performance goal. The pushover analysis in general manner is able to predict the general trend in platform response, for example, occurrence of a weak link in the pile foundation in the original platform model. However, the results can be biased depending on the pushover pattern. For example, choosing a pattern based on a "first mode lateral load pattern" presented by Chopra and Goel [40] showed the "overturning failure mechanism" of response in all three models studied herein where the pile plugged out of the soil. Consequently, if the pushover analysis is going to be conducted for ductility demand evaluations within the design stage, the authors recommend that at least two different load patterns with different conceptual 


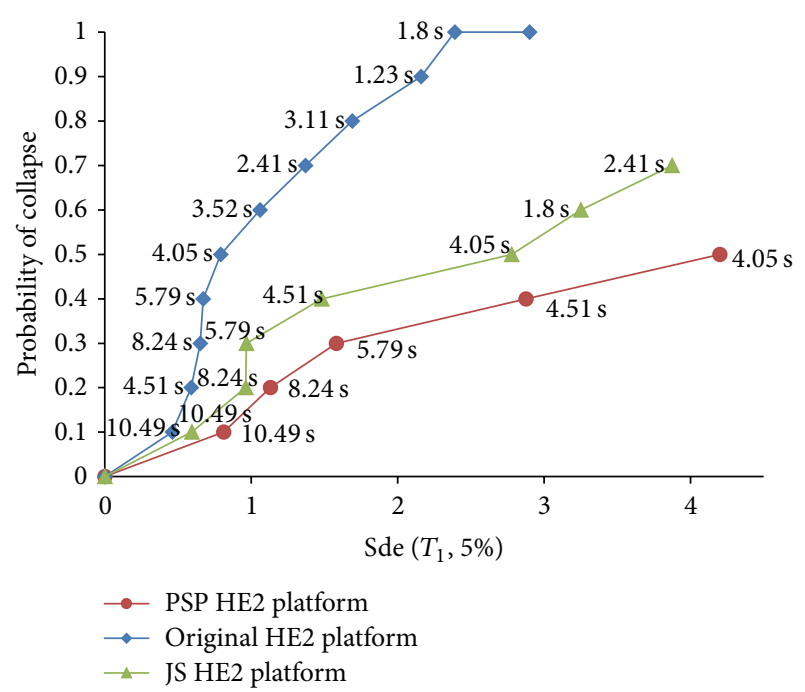

FIGURE 20: Collapse fragility curve for two platforms model (data labels are pulse period of records).

natures be chosen for pushover analysis, and the desired response should be checked with these load patterns.

(b) Two main requirements, the strength and ductility level requirements, stipulated in API RP2A-WSD [30] recommended practice must be considered in the seismic design of JTOPs. Strength level is required to make the platform adequately sized for strength and stiffness to ensure that there is no significant structural damage during an earthquake vibration, which has a reasonable likelihood of not being exceeded during the life of the structure. Usually, it is anticipated that the structural part remains elastic during this phase of design. The elastic response spectrum method is commonly used (both in the platform studied here and in other studies in literature (El-Din and Kim [12])) in the design of the platform under the strength level ground vibration. Under the ductility level ground vibration, the platform could respond in its nonlinear range of deformation, and it is only necessitated that the platform maintains its stability under the influence of gravity loading. Since the inelastic characteristic of its behavior requires an additional detailed knowledge and experience for analyzing the structure in this range and the design software should also equipped with effective elements and material constitutive behavior capable of simulating nonlinear behavior, the response predictions under the ductility loading demands could be biased or even may be neglected by design engineers. In addition to this, some commercial design software such as Sacs has only the capability to increase the applied load pattern in a load control manner, which limit the pushover analysis to the first component failure and avoids postnonlinear behavior. In light of these facts, a procedure is presented to be conducted during the elastic response spectrum method to avoid pile weak link behavior in rare earthquake events. It is recommended to remove the near field soil bearing springs at a distance of 4 to 6 times the pile diameter from the mud line level. Then, the design response spectrum procedure should be repeated with the modified model, and the pile should be sized in a manner that the unity check in the piles becomes lower than the unity check in the jacket members. This procedure has been verified for both the modified models presented in this paper and for two other modifications to the original model which are not reported here. The main reasoning behind this suggested procedure relies on the fact that, when the intensity of seismic vibration becomes stronger, the soil in the upper parts of the pile reaches its ultimate shearing capacity and the piles lose their lateral bearings.

(c) The analysis results reported in this paper (both the dynamic and static analysis procedures) reveal that weak pile strength relative to jacket members can significantly reduce the platform's ultimate capacity. On the other hand, it is believed that although the consistent strength and stiffness of piles and jacket part are mostly desired to have an optimum balance between reliable performance and smaller sized members, the stronger pile foundation relative to the jacket part shows a better performance than its counterpart. Consequently, it is recommended that, during the design phase, the maximum unity checks in the pile foundation have better be "much lower" than the maximum unity checks in the jacket members. It should be noted that while the maximum unity check in jacket members dominates the pile foundation unity check in the original HE2 platform, the weak link behaviors in the pile foundation are still observed in this case.

\section{Conclusions}

Incremental Dynamic Analysis of a newly designed and installed well-head steel offshore platform was performed. In the same vein, a numerical model was developed to assess the performance of this structure under a suit of 10 pulse-type near-fault ground motion records. OpenSees finite element software was used to create the numerical model of the platform considering buckling and postbuckling behavior of bracing members and material low-cycle fatigue effects. In order to consider soil-pile-structure interaction effects, the near-field soil was modeled using Beam on Nonlinear Winkler Foundation method. Furthermore, the geotechnical capabilities of OpenSees were utilized to compute free-field response of soil layers. Some individual IDA curves in terms of maximum storey-like drift ratio per unit length of pile and maximum interstorey drift ratio of jacket bracing storeys were presented. It was shown that the braces of the jacket storeys do not buckle and the only source of nonlinearity in this platform is the pile foundation. The earlier creation of plastic 
hinges in the upper part of the pile foundation caused this region of pile to work as a weak storey and prevented other parts of the platform from meeting at a nonlinear range of response.

In order to investigate the importance of pile foundation behavior in the whole platform response and the probability of collapse, two modified models of original platform were created slightly increasing the diameter of the pile foundation and also softening the jacket part. These changes in platform structural models led to the enhancement of platform seismic ultimate strength. It was found that the proportional distribution of nonlinear behavior in the pile foundation and jacket part is the key factor in enhancement of ultimate strength of platform. This uniform distribution of strength and stiffness along the platform profile significantly improved the ductility capacity of the structure in the modified models compared to the original model, which led to higher seismic energy dissipation capacity of platform. In some records, the platform did not reach its final capacity or in other words collapse did not occur. The reason for this phenomenon is that, in some scales of these records, the input ground motion is so strong that it drives the soil to its final capacity and, due to strain softening behavior of soil, no more load is transferred to the platform structural part. The collapse fragility curve of these modified platform models revealed a significant reduction in the probability of collapse relative to the original platform. This reduction in probability of collapse is believed to be the results of (1) a slight increase in the bending strength of the pile in pile strengthened model, (2) uniform distribution of damage in the pile foundation and jacket part, and (3) passing the soil ultimate shear strength in higher intensity levels of some records. It should be noted that the pulse period of records was found to be the most important factor influencing the collapse of all platform models. The higher the pulse period of the record, the lower the IM at which the collapse occurs. There seemed to be a monotonic relationship between the pulse period of record and the collapse probability. This fact is in contrast to the building structures dynamic results for which $T_{p} / T=2$ (i.e., a $T_{p}$ that is twice as long as the elastic period of an oscillator) seems to be the most damaging case because the effectively elongated period drifts toward the peaks of the pulse period, $T_{p}$ (Alavi and Krawinkler [41]). Comparing the results of the three platforms dynamic analysis, it was concluded that the pile foundation plays a paramount role in dynamic response of platforms and can alter the ultimate strength of the platform together with its collapse capacity to a higher degree. The results of this study reveal that much more investigations should be focused on the coupling behavior of pile foundation and super structure of JTOPs. Moreover, current codes of Fixed Offshore Platforms design do not address direct procedures for evaluating coupling interaction of pile foundation and jacket part of JTOPs. On the basis of the findings from this paper, it is recommended that some basic requirements should be developed in order to ensure that the coupling ductility of the various parts of the platform is optimized during the design process. For instance, this study recommended removing the near-field soil bearing springs at a distance of 4 to 6 times the pile diameter from the mud line level during the design phase.

\section{Conflict of Interests}

The authors declare that there is no conflict of interests regarding the publication of this paper.

\section{References}

[1] E. Gates, W. Marshal, and S. A. Mahin, "Analytical methods for determining the ultimate earthquake resistance of fixed offshore structures," in Proceedings of the Offshore Technology Conference, Houston, Tex, USA, 1997.

[2] K. Kayvani and F. Barzegar, "Hysteretic modelling of tubular members and offshore platforms," Engineering Structures, vol. 18, no. 2, pp. 93-101, 1996.

[3] M. Mortazavi and R. G. Bea, "Experimental validation of the ultimate limit state limit equilibrium analysis (ULSLEA) with results from frame tests," in Proceedings of the 7th International Offshore and Polar Engineering Conference, pp. 321-327, Honolulu, Hawaii, USA, May 1997.

[4] B. Asgarian and H. Agheshlui, "Reliability-based earthquake design of jacket-type offshore platforms considering pile-soilstructure interaction," American Journal of Applied Sciences, vol. 6, no. 4, pp. 631-637, 2009.

[5] A. A. Golafshani, M. R. Tabeshpour, and Y. Komachi, "FEMA approaches in seismic assessment of jacket platforms (case study: ressalat jacket of Persian gulf)," Journal of Constructional Steel Research, vol. 65, no. 10-11, pp. 1979-1986, 2009.

[6] V. A. Zayas, S. A. Mahin, and E. P. Popov, "Cyclic inelastic behavior of steel offshore structures," Report no. UCB/EERC80/27, University of California, Berkeley, Calif, USA, 1980.

[7] M. R. Honarvar, M. R. Bahaari, B. Asgarian, and P. Alanjari, "Cyclic inelastic behavior and analytical modelling of pile-leg interaction in jacket type offshore platforms," Applied Ocean Research, vol. 29, no. 4, pp. 167-179, 2007.

[8] A. A. Golafshani, M. Kia, and P. Alanjari, "Local joint flexibility element for offshore plateforms structures," Marine Structures, vol. 33, pp. 56-70, 2013.

[9] R. G. Bea and C. Young, "Loading and capacity effects on platform performance in extreme condition storm waves and earthquakes," in Proceedings of the 25th Annual Offshore Technology Conference, pp. 45-60, Houston, Tex, USA, May 1993.

[10] B. Peng, B. Chang, and C. Llorente, "Nonlinear dynamic soilpile-structure interaction analysis of a deepwater platform for ductility level earthquakes," in Proceedings of the Offshore Technology Conference, Houston, Tex, USA, February 2005.

[11] K. Bargi, S. R. Hosseini, M. H. Tadayon, and H. Sharifian, "Seismic response of a typical fixed jacket-type offshore platform (spd1) under sea waves," Open Journal of Marine Science, vol. 1, no. 2, pp. 36-42, 2011.

[12] M. N. El-Din and J. Kim, "Sensitivity analysis of pile-founded fixed steel jacket platforms subjected to seismic loads," Ocean Engineering, vol. 85, pp. 1-11, 2014.

[13] J. Ou, X. Long, Q. S. Li, and Y. Q. Xiao, "Vibration control of steel jacket offshore platform structures with damping isolation systems," Engineering Structures, vol. 29, no. 7, pp. 1525-1538, 2007.

[14] S. A. Mousavi, K. Bargi, and S. M. Zahrai, "Optimum parameters of tuned liquid columngas damper for mitigation of 
seismic-induced vibrations of offshore jacket platforms," Structural Control and Health Monitoring, vol. 20, no. 3, pp. 422-444, 2013.

[15] H.-N. Li, X.-Y. He, and T.-H. Yi, "Multi-component seismic response analysis of offshore platform by wavelet energy principle," Coastal Engineering, vol. 56, no. 8, pp. 810-830, 2009.

[16] M. M. Memarpour, M. Kimiaei, M. Shayanfar, and M. Khanzadi, "Cyclic lateral response of pile foundations in offshore platforms," Computers and Geotechnics, vol. 42, pp. 180-192, 2012.

[17] D. Vamvatsikos and C. A. Cornell, "Incremental dynamic analysis," Earthquake Engineering and Structural Dynamics, vol. 31, no. 3, pp. 491-514, 2002.

[18] M. A. Assareh and B. Asgarian, "Nonlinear behavior of single piles in jacket type offshore platforms using incremental dynamic analysis," American Journal of Applied Sciences, vol. 5, no. 12, pp. 1793-1803, 2008.

[19] B. Asgarian and A. Ajamy, "Seismic performance of jacket type offshore platforms through incremental dynamic analysis," Journal of Offshore Mechanics and Arctic Engineering, vol. 132, no. 3, Article ID 031301, 2010.

[20] M. N. El-Din and J. Kim, "Seismic performance evaluation and retrofit of fixed jacket offshore platform structures," Journal of Performance of Constructed Facilities, Article ID 04014099, 2014.

[21] S. D. Hasan, N. Islam, and K. Moin, "A review of fixed offshore platforms under earthquake forces," Structural Engineering and Mechanics, vol. 35, no. 4, pp. 479-491, 2010.

[22] J. W. Baker, S. K. Shahi, and N. Jayaram, "New ground motion selection procedures and selected motions for the peer transportation research program," PEER Report, Pacific Earthquake Engineering Research Center, University of California, Berkeley, Calif, USA, 2011.

[23] P. G. Somerville, N. F. Smith, R. W. Graves, and N. A. Abrahamson, "Modification of empirical strong ground motion attenuation relations to include the amplitude and duration effects of rupture directivity," Seismological Research Letters, vol. 68, no. 1, pp. 199-222, 1997.

[24] N. N. Ambraseys and C. P. Melville, A History of Persian Earthquakes, Cambridge University Press, Cambridge, UK, 1982.

[25] United States Geological Survey, USGS Earthquake Hazards Program, http://earthquake.usgs.gov/earthquakes/eqinthenews/ 2005/usfyag/\#details.

[26] K. Hessami and F. Jamali, "Explanatory notes to the map of major active faults of Iran," Journal of Seismology and Earthquake Engineering, vol. 8, no. 1, pp. 1-11, 2006.

[27] M. K. Mohamadi and S. Sherkati, "The rupture analysis in South Pars gas field," Oil and Gas Exploration and Production, vol. 1390, no. 77, pp. 43-49, 2011 (Persian).

[28] M. Abyani, Seismic reliability of Jacket Type Offshore Platform with considering epistemic uncertainty of damping ratio based on geometric mean [M.S. thesis], K.N.Toosi University of Technology, Tehran, Iran, 2013, (Persian).

[29] PEER Transportation Systems Research Program (TSRP), http://peer.berkeley.edu/transportation/projects/ground-motionstudies-for-transportation-systems/.

[30] American Petroleum Institute, Recommended Practice for Planning, Designing and Constructing Fixed Offshore PlatformsWorking Stress Design, API Recommended Practice 2A-WSD, RP 2A-WSD, 21st edition, 2007.
[31] S. Mazzoni, F. McKenna, M. Scott, and G. Fenves, Open System for Earthquake Engineering Simulation (OpenSees)-OpenSees Command Language Manual, University of California, Berkeley, Calif, USA, 2007.

[32] M. Menegotto and P. Pinto, "Method of analysis for cyclically loaded reinforced concrete plane frame including changes in geometry and non-elastic behavior of elements under combined normal force and bending," in Proceedings of the IABSE Symposium on Resistance and Ultimate Deformability of Structures Acted on by Well Defined Repeated Loads, 1973.

[33] R. de Souza, Forced-based finite element for large displacement inelastic analysis of frames [Ph.D. thesis], University of California, Berkeley, Calif, USA, 2000.

[34] B. Asgarian, A. A. Aghakouchak, and R. G. Bea, "Nonlinear analysis of jacket-type offshore platforms using fiber elements," Journal of Offshore Mechanics and Arctic Engineering, vol. 128, no. 3, pp. 224-232, 2006.

[35] P. Uriz and S. A. Mahin, Toward Earthquake-Resistant Design of Concentrically Braced Steel-Frame Structures, Pacific Earthquake Engineering Research Center, University of California, Berkeley, Calif, USA, 2008.

[36] R. W. Boulanger, B. L. Kutter, S. J. Brandenberg, P. Singh, and D. Chang, "Pile foundations in liquefied and aterally spreading ground during earthquakes: centrifuge experiments and analyses," Tech. Rep. UCD/CGM-03/01, Center for Geotechnical Modeling, University of California, Davis, Calif, USA, 2003.

[37] R. W. Boulanger, C. J. Curras, B. L. Kutter, D. W. Wilson, and A. Abghari, "Seismic soil-pile-structure interaction experiments and analyses," Journal of Geotechnical and Geoenvironmental Engineering, vol. 125, no. 9, pp. 750-759, 1999.

[38] Z. Yang, A. Elgamal, and E. Parra, "Computational model for cyclic mobility and associated shear deformation," Journal of Geotechnical and Geoenvironmental Engineering, vol. 129, no. 12, pp. 1119-1127, 2003.

[39] M. Zarrin, B. Asgarian, and R. Foulad, "A review on factors affecting seismic pile response analysis in soft clay and dense liquefying sand," Coupled System Mechanics. In press.

[40] A. K. Chopra and R. K. Goel, "Modal pushover analysis procedure to estimate seismic demands for buildings: theory and preliminary evaluation," PEER Report 2001/3, Pacific Earthquake Engineering Research Center, University of California, Berkeley, Calif, USA, 2001.

[41] B. Alavi and H. Krawinkler, "Effects of near-field ground motion on frame structures," Tech. Rep. 138, John A. Blume Earthquake Engineering Center, Department of Civil and Environmental Engineering, Stanford University, Stanford, Calif, USA, 2001. 

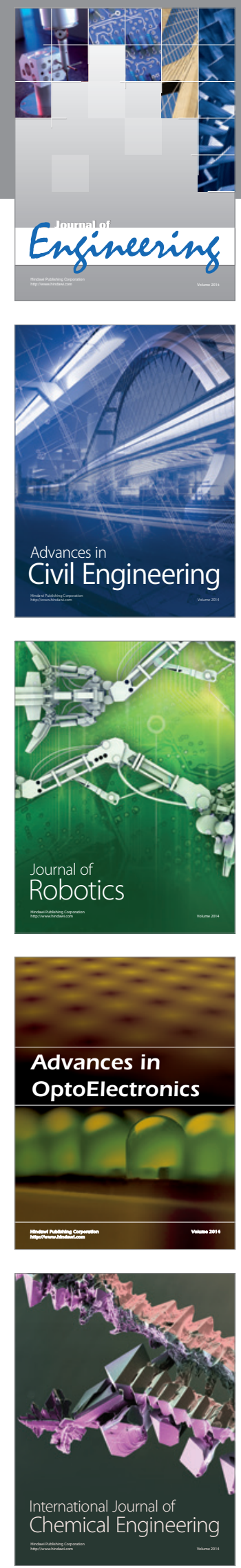

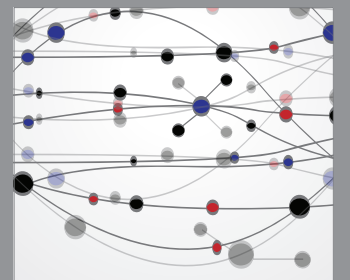

The Scientific World Journal
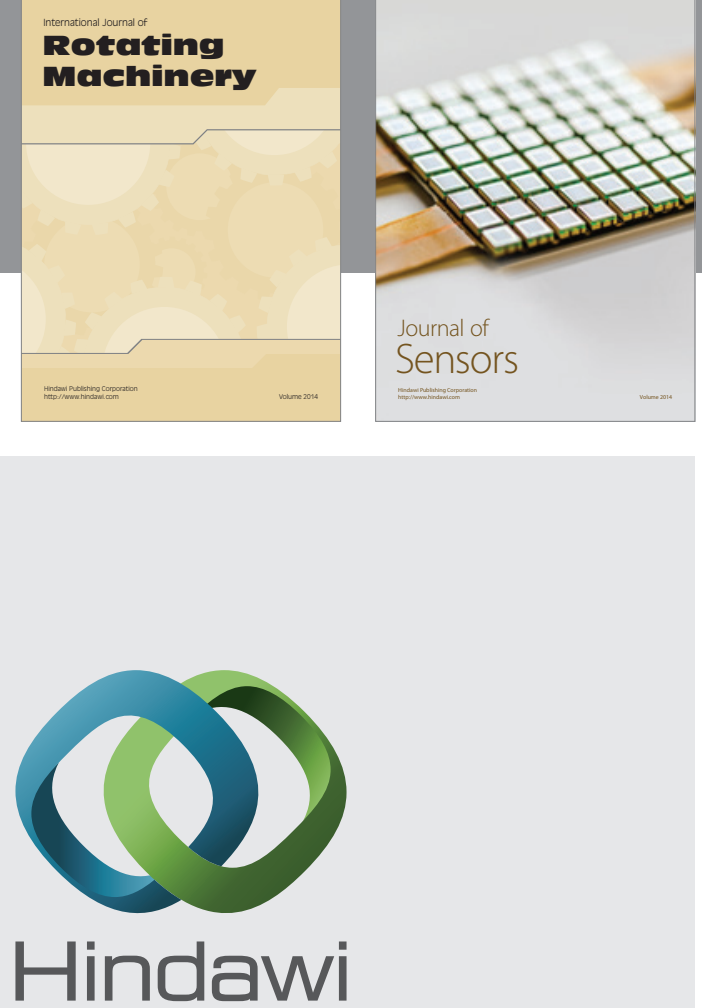

Submit your manuscripts at http://www.hindawi.com
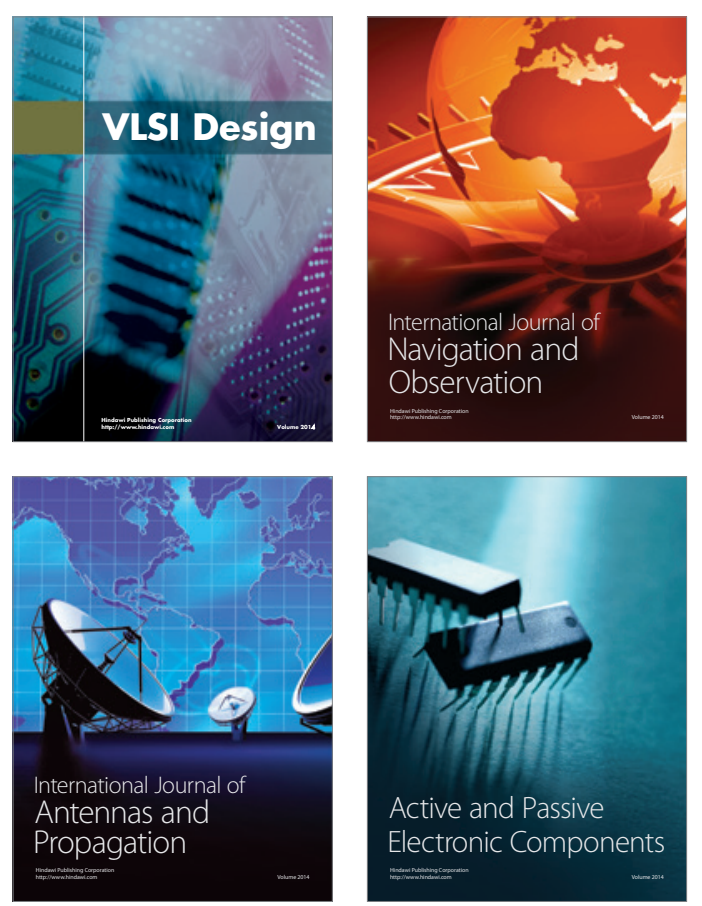
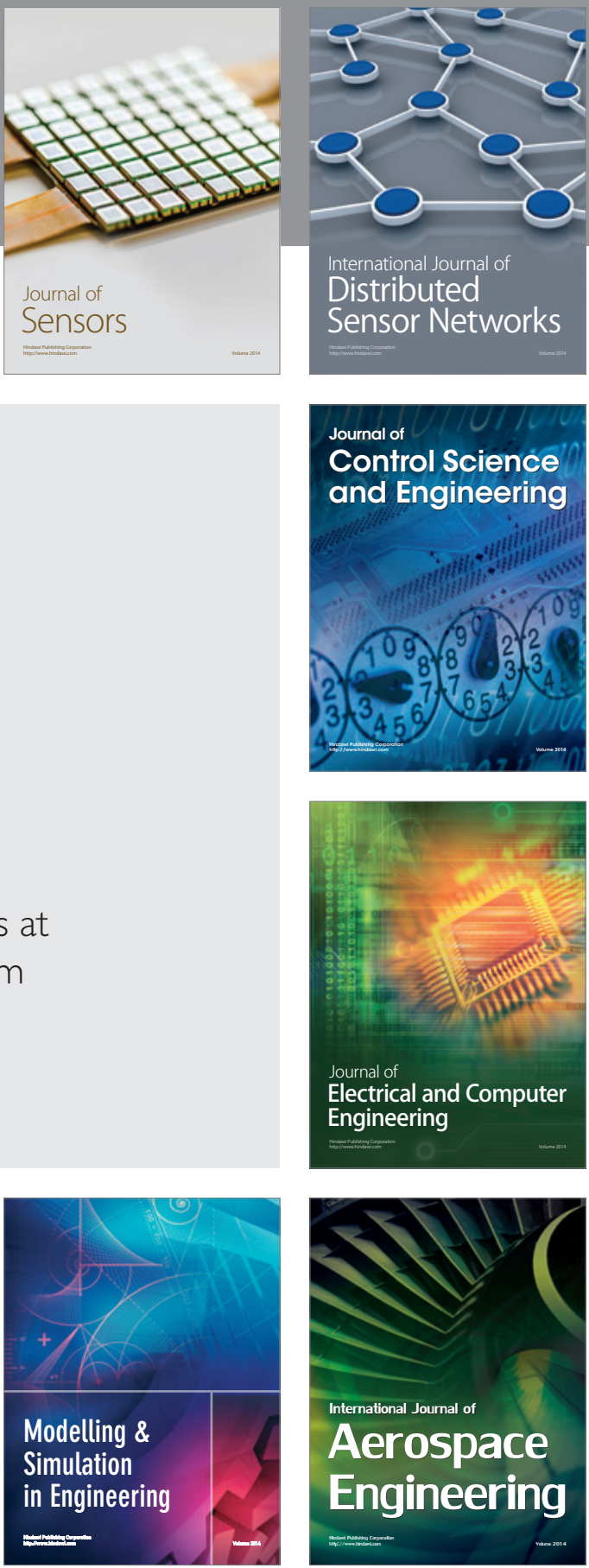

Journal of

Control Science

and Engineering
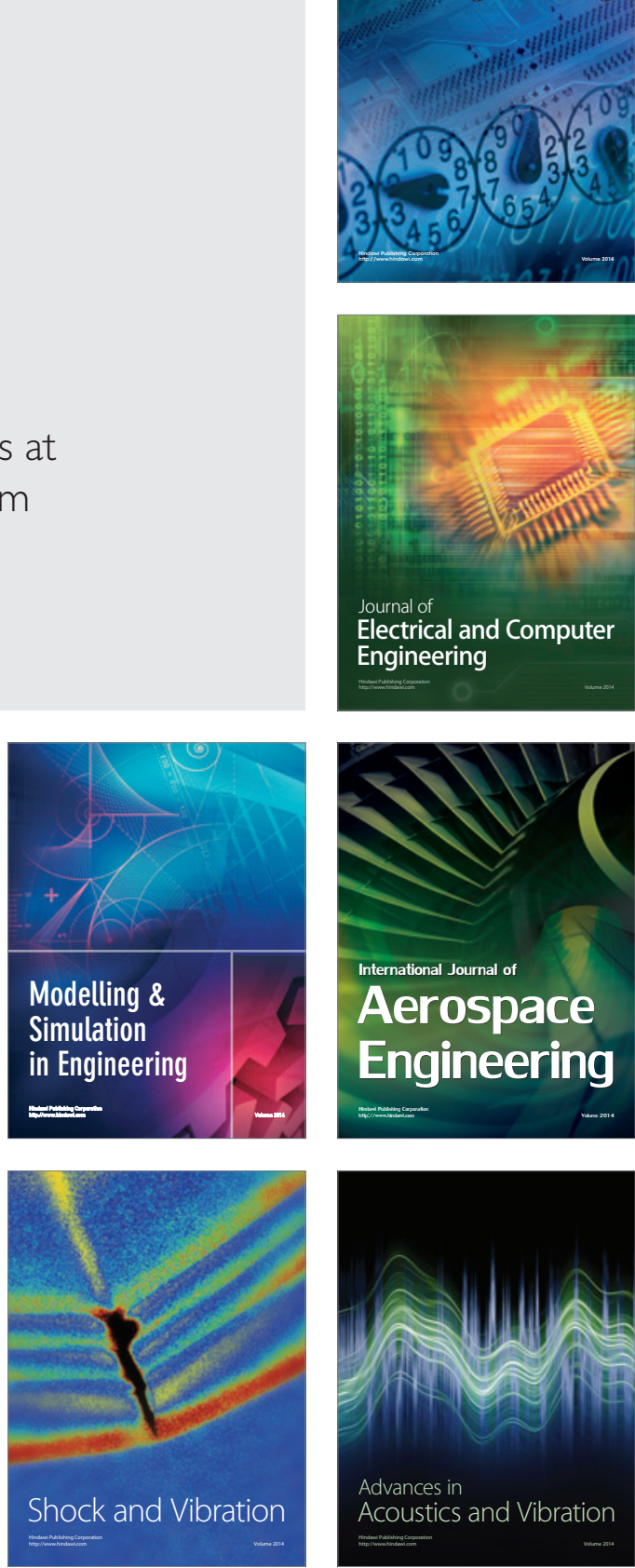